\title{
IL-10-producing NKT10 cells are a distinct regulatory invariant NKT cell subset
}

\author{
Duygu Sag, ${ }^{1}$ Petra Krause, ${ }^{2}$ Catherine C. Hedrick, ${ }^{1}$ Mitchell Kronenberg, ${ }^{2}$ and Cerhard Wingender ${ }^{2}$ \\ 'Division of Inflammation Biology and 'Division of Developmental Immunology, La Jolla Institute for Allergy and Immunology, La Jolla, California, USA
}

\begin{abstract}
Invariant natural killer T (iNKT) cells rapidly produce copious amounts of multiple cytokines after activation, thereby impacting a wide variety of different immune reactions. However, strong activation of $i$ NKT cells with $\alpha$-galactosylceramide ( $\alpha$ GalCer) reportedly induces a hyporeactive state that resembles anergy. In contrast, we determined here that iNKT cells from mice pretreated with $\alpha$ GalCer retain cytotoxic activity and maintain the ability to respond to TCR-dependent as well as TCR-independent cytokine-mediated stimulation. Additionally, $\alpha$ GalCer-pretreated $i N K T$ cells acquired characteristics of regulatory cells, including production and secretion of the immunomodulatory cytokine IL-10. Through the production of IL-10, $\alpha$ GalCer-pretreated iNKT cells impaired antitumor responses and reduced disease in experimental autoimmune encephalomyelitis, a mouse model of autoimmune disease. Furthermore, a subset of iNKT cells with a similar inhibitory phenotype and function were present in mice not exposed to $\alpha$ GalCer and were enriched in mouse adipose tissue and detectable in human PBMCs. These data demonstrate that IL-10-producing iNKT cells with regulatory potential (NKT10 cells) represent a distinct $i$ NKT cell subset.
\end{abstract}

\section{Introduction}

Invariant natural killer $\mathrm{T}$ ( $i \mathrm{NKT}$ ) cells are a unique subset of $\mathrm{T}$ lymphocytes characterized by an invariant V $\alpha 14$ to J $\alpha 18$ TCR rearrangement $(\mathrm{V} \alpha 14 i)$ in mice and an orthologous rearrangement (Vo24i) in humans. $i$ NKT cells recognize glycolipids presented by CD1d, a nonpolymorphic MHC class I homolog. After activation, $i$ NKT cells rapidly produce copious amounts of Th1, Th2, and Th17 cytokines, impacting a dazzling variety of different immune reactions, including responses to pathogens and tumors (1-5). The synthetic model antigen $\alpha$-galactosylceramide ( $\alpha \mathrm{GalCer}$ ), a potent agonist of mouse and human $i$ NKT cells, has been tested in clinical trials for the treatment of cancer patients, and it is under continuing development as a therapeutic agent (1-7). The influence of $i$ NKT cells can, however, be unpredictable, and they may exhibit opposing effects on tumor growth, inflammation, and other responses (4). Furthermore, the long-term effects of the treatment of animals and patients with $\alpha$ GalCer are incompletely defined, and conflicting outcomes have been reported (8-11). Based on earlier publications $(9,10)$, in vivo treatment of mouse $i$ NKT cells with $\alpha \mathrm{GalCer}$ is thought to lead to a general hyporesponsive state of $i$ NKT cells. Here, we report that the strong activation mediated by $\alpha \mathrm{GalCer}$ does not lead to anergy or a complete unresponsiveness of iNKT cells, but rather induces a novel state characterized by IL-10 production. Importantly, a subset of $i$ NKT cells with a similar phenotype and function were detected even in untreated mice and in PBMCs from healthy donors, indicating that $i \mathrm{NKT}$ cells with a similar function are present in vivo under steady-state conditions. This indicates that regulatory $i$ NKT cells occur naturally and that they represent a novel subset that we term NKT10 cells.

Conflict of interest: The authors have declared that no conflict of interest exists Submitted: February 10, 2014; Accepted: June 5, 2014.

Reference information: J Clin Invest. 2014;124(9):3725-3740. doi:10.1172/JCI72308.

\section{Results}

$\alpha$ GalCer-pretreated iNKT cells display an increased frequency of proliferating cells. $\alpha$ GalCer-pretreated $i$ NKT cells have been shown to have a long-term reduction in proliferation and proinflammatory cytokine production upon antigen rechallenge $(9,10,12)$, which has been interpreted as a general loss of effector functions. However, when we analyzed the expression of Ki67 in $i$ NKT cells as a surrogate marker for proliferation on a single-cell level, the proportion of proliferating $i \mathrm{NKT}$ cells at steady state, when analyzed ex vivo, was actually higher in animals pretreated with $\alpha$ GalCer 1 month earlier (Figure 1, A and B). Although Ki67 is expressed in all active phases of the cell cycle (G1, S, G2, and mitosis), it only marks cells with the potential to divide (13), and anergic T lymphocytes have been reported to be arrested in the G1 phase of the cell cycle (14). Therefore, we performed a detailed cell-cycle analysis and measured proliferation directly by BrdU incorporation. Congruent with the Ki67 data, significantly more $\alpha \mathrm{GalCer}$-pretreated $i$ NKT cells incorporated BrdU than did control $i$ NKT cells (Figure $1, \mathrm{~A}-\mathrm{C}$ ), and significantly more cells were detected in the $\mathrm{S}$ phase of the cell cycle (Figure 1, C and D). However, the ratio of cells in the early $S$ phase compared with that in the late $S$ phase was similar in control and $\alpha \mathrm{GalCer}$-pretreated $i \mathrm{NKT}$ cells (Figure 1E), suggesting that the cell-cycle progression of $\alpha$ GalCer-pretreated $i$ NKT cells was undisturbed. We also performed a genome-wide gene expression analysis of untreated and $\alpha$ GalCer-pretreated $i$ NKT cells using microarrays. In agreement with the increased proliferation observed by flow cytometry, genes that promote transition through the cell cycle were upregulated in $\alpha \mathrm{GalCer}$ pretreated $i$ NKT cells, including genes that are required for cells to transit beyond the G1 phase, such as cyclin A, B, and E (Supplemental Figure 1A; supplemental material available online with this article; doi:10.1172/JCI72308DS1). Additionally, genes for cellcycle inhibitors were not expressed or did not change consistently 


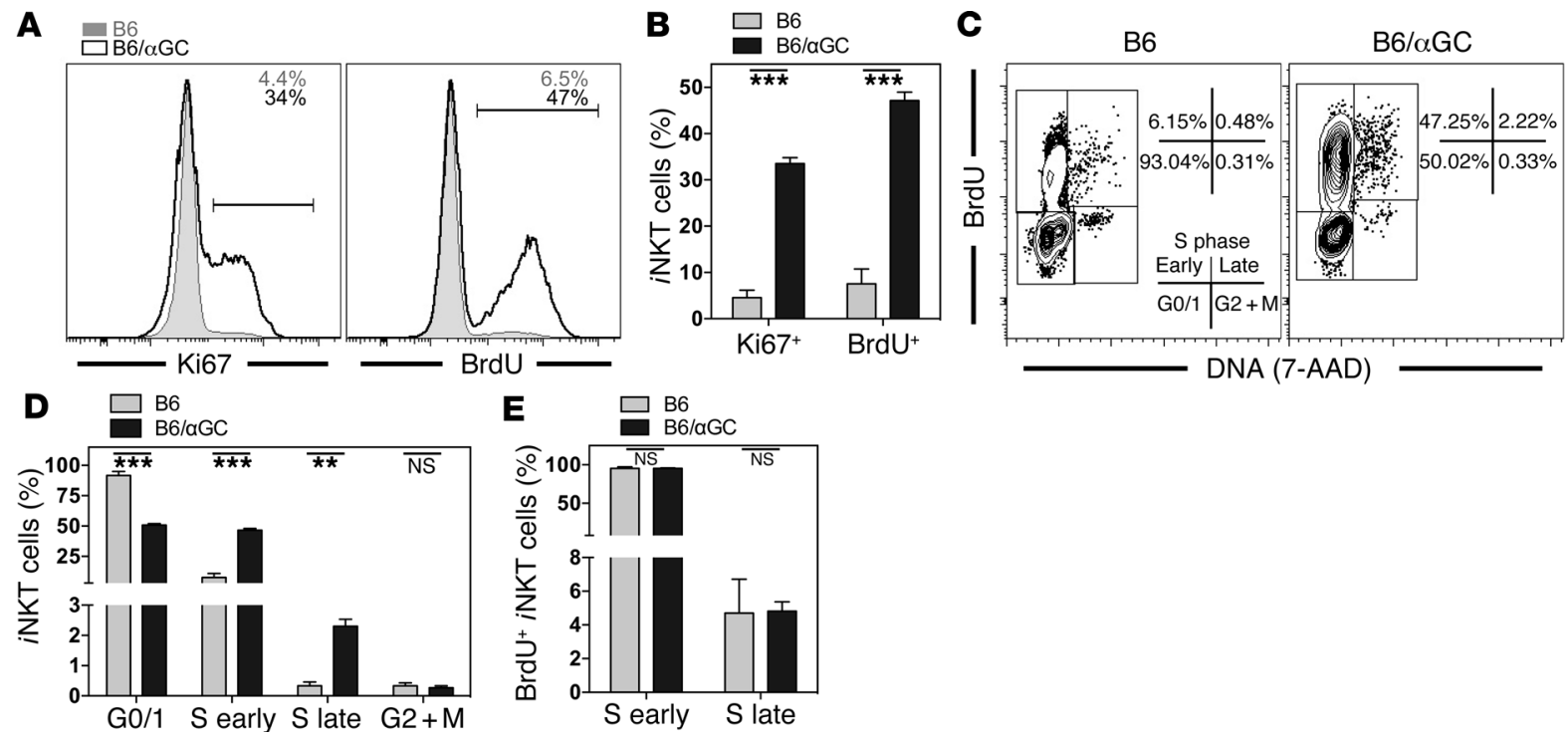

Figure 1. $\alpha$ GalCer-pretreated iNKT cells display an increased frequency of proliferating cells. (A and B) Steady-state expression of Ki67 and BrdU (3-day pulse) in splenic $i N K T$ cells from C57BL/ 6 control (B6, tinted area) or C57BL/6 mice injected 1 month earlier with $4 \mu \mathrm{g} \alpha \mathrm{GalCer}$ (B6/ $\alpha \mathrm{GC}$, black line). Representative data (A) and a summary graph (B) are shown. Numbers in the histograms denote the percentage of positive cells within the depicted gate from the indicated mice. (C-E) Expression of DNA (labeled with 7-AAD) and BrdU (3-day pulse) in splenic iNKT cells from C57BL/6 control (B6) or C57BL/6 mice injected 1 month earlier with $4 \mu \mathrm{g} \alpha \mathrm{GalCer}(\mathrm{B} 6 / \alpha \mathrm{GC})$. Representative data (C) and a summary graph (D) are shown. Numbers in $\mathbf{C}$ denote the percentages in the respective rectangles. Definition of the cell-cycle stages is given in the left dot plot. $M$, mitosis. (E) Graphic representation of the frequency of 7-AAD(S early) and 7-AAD+ (S late) cells, considering BrdU+ ${ }^{+}$NKT cells. Representative data from at least 3 independent experiments (3-4 mice/group) are shown for each panel.

in $\alpha$ GalCer-pretreated $i$ NKT cells (Supplemental Figure 1B). Therefore, whereas anergic $\mathrm{T}$ cells show impaired proliferation (15), our data demonstrate that $\alpha$ GalCer-pretreated $i$ NKT cells display increased steady-state proliferation.

$\alpha$ GalCer-pretreated iNKT cells retain antigen-specific cytotoxicity. Effector functions of $i$ NKT cells are not limited to cytokine production, as activated $i$ NKT cells display potent cytotoxic activity (16). To test whether $\alpha$ GalCer pretreatment would affect the cytotoxic potential of $i \mathrm{NKT}$ cells, we measured the in vivo cytotoxic activity of naive and $\alpha \mathrm{GalCer}$-pretreated mice. As shown in Figure $2 \mathrm{~A}$, the $\alpha \mathrm{GalCer}$-specific in vivo cytotoxicity tended to be lower in $\alpha \mathrm{Gal}-$ Cer-pretreated mice compared with that in control animals, but this decrease did not reach statistical significance in the majority (6 of 10) of experiments. $i$ NKT cell thymic emigrants that reached the periphery after the injected $\alpha \mathrm{GalCer}$ was cleared from the circulation could account for the cytotoxicity. To exclude this, we repeated the in vivo cytotoxicity assay with animals that had been thymectomized before the injection of $\alpha \mathrm{GalCer}$. However, we observed no significant difference between the wild-type and thymectomized groups (Figure 2A), indicating that recent thymic emigrants (RTEs) cannot account for the remaining cytotoxicity in the $\alpha$ GalCer-pretreated animals. We also noted significantly lower frequencies of splenic and liver $i \mathrm{NKT}$ cells in the $\alpha$ GalCer-pretreated mice compared with those in control animals (Figure 2A and data not shown), suggesting that the small decrease in the in vivo cytotoxicity could be a consequence of lower numbers of effector $i \mathrm{NKT}$ cells rather than a reduction in their intrinsic functionality.

It could be argued that the $i \mathrm{NKT}$ cell population consists of a cytotoxic subset that is unaffected by previous $\alpha \mathrm{GalCer}$ treatment and a cytokine-producing subset that can be anergized by $\alpha$ GalCer.
To distinguish between these options, we used a single-cell assay by measuring CD107a and CD107b externalization as an indicator of $i$ NKT cell degranulation (17). To this end, we stimulated splenocytes from control and $\alpha$ GalCer-pretreated mice with plate-bound $\alpha \mathrm{CD} 3 \varepsilon$ antibody and analyzed the binding of $\alpha \mathrm{CD} 107 \mathrm{a} / \mathrm{b}$ antibodies by $i$ NKT cells. We observed no difference in the frequency or intensity of $i$ NKT cells that bound CD107a and CD107b between the control and $\alpha$ GalCer-pretreated splenocytes (Figure 2, B and $\mathrm{C}$ ), indicating that the degranulation of $i$ NKT cells is comparable between wild-type and $\alpha$ GalCer-pretreated $i$ NKT cells.

Stimulation of $i$ NKT cells with $\alpha$ GalCer can protect mice against lung metastases resulting from challenge with B16 melanoma, and Parekh et al. (9) reported that this protection is lost in $\alpha$ GalCer-pretreated mice. However, B16 melanoma cells do not express CD1d (16), excluding the possibility that the tumor cells serve as direct targets of $i$ NKT cell cytotoxicity. Indeed, it is known that the cytotoxicity against B16 in this model is dependent on NK cell trans-activation, induced in part by $i$ NKT cell-derived IFN- $\gamma$ (18, 19). We previously showed, however, that B16 stably transfected with CD1d (B16-CD1d) and loaded with $\alpha$ GalCer can be a cognate target for $i$ NKT cells, in which case the tumor cells are eliminated efficiently in vivo in an antigen-specific manner (16). We used the B16-CD1d cell line to directly address whether $\alpha$ GalCer-pretreated $i$ NKT cells could protect mice against this melanoma. In line with previous data (9), we found that administration of $\alpha \mathrm{GalCer}$ with B16-CD1d tumor challenge could protect mice from metastases (Figure 2D, compare bars 1 and 2), but $i$ NKT cells were not effective in mice pretreated with $\alpha$ GalCer (Figure 2D, bars 4 and 5). This is consistent with the impaired IFN- $\gamma$ release by $i$ NKT cells previously exposed to $\alpha$ GalCer as reported before $(9,10)$ and shown below. 


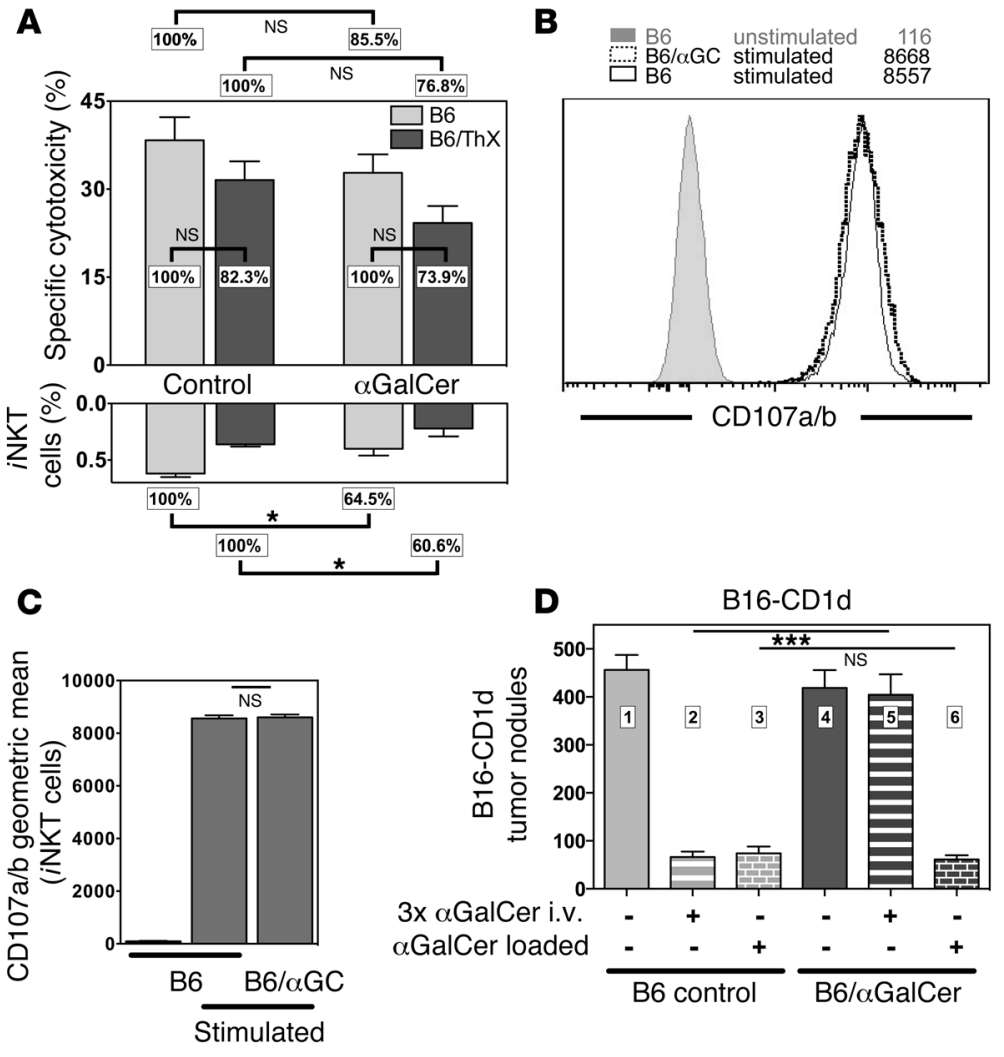

Figure 2. $\alpha$ GalCer-pretreated $i$ NKT cells retain antigenspecific cytotoxicity. (A) Upper panel: Normalized data on $\alpha$ GalCer-specific in vivo cytotoxicity in spleen 4 hours after injection of primary splenic B cell targets into $\mathrm{C} 57 \mathrm{BL} / 6$ (B6) and previously thymectomized C57BL/6 mice (B6/ThX) (3 mice/group), which were either left untreated (control) or i.v. injected 1 month earlier with $4 \mu \mathrm{g} \alpha \mathrm{GalCer}$. iNKT celldeficient $J \alpha 18^{-/-}$mice injected with $B$ cell targets provided the negative control. $P=0.797$ for B6 versus B6/ThX. Lower panel: Relative frequencies of splenic $i$ NKT cells in the indicated groups. $P=0.372$ for B6 versus B6/ThX. (B and C) Splenocytes enriched for $i$ NKT cells from the indicated mice were incubated for 5 hours in plates coated with $\alpha \mathrm{CD} 3 \varepsilon$ antibodies in the presence of $\alpha \mathrm{CD} 107 \mathrm{a}$ and $\alpha \mathrm{CD} 107 \mathrm{~b}$ antibodies. Representative data (B) and a summary graph (C) are shown. Numbers in $\mathbf{B}$ denote the geometric mean values. (D) Lung metastases in $\mathrm{B} 6$ control or $\mathrm{B} 6 / \alpha$ GalCer mice that were i.v. injected with $1 \times 10^{5}$ B16-CD1d melanoma cells (4-7 mice/group). B16-CD1d cells were either untreated or loaded in vitro with $\alpha$ GalCer ( $250 \mathrm{ng} / \mathrm{ml}, 1$ hour), as indicated. Indicated mice were additionally i.v. injected 3 times (days 0,4 , and 7) with $1 \mu \mathrm{g}$ $\alpha$ GalCer. Representative data from at least 2 independent experiments are shown in each panel.
In contrast, when $\alpha$ GalCer was loaded directly onto the B16-CD1d cells, which will efficiently elicit cytotoxic function, we observed no difference in tumor protection between control and $\alpha \mathrm{GalCer}-$ pretreated mice (Figure 2D, bar 3 versus bar 6). Therefore, we conclude that cytotoxicity induced by cognate antigen recognition is unimpaired in $\alpha$ GalCer-pretreated $i$ NKT cells.

Effective TCR signaling of aGalCer-pretreated iNKT cells. To directly assess the response of $\alpha$ GalCer-pretreated $i$ NKT cells to TCR triggering, we used Nur77GFP reporter mice. The Nr4a1 (Nur77) gene is an orphan nuclear receptor that is an immediate-early gene whose expression is increased by TCR stimulation. Therefore, in these mice, GFP expression is a sensitive and faithful reporter of TCR activation in $i$ NKT cells (20). Control Nur77 $7^{G F P}$ mice and $N u r 77^{G F P}$ mice pretreated with $\alpha$ GalCer were challenged with $\alpha$ GalCer, and we analyzed GFP expression by $i$ NKT cells 1 hour later. Virtually all $i \mathrm{NKT}$ cells from both $\alpha$ GalCer-pretreated and naive mice induced GFP expression following $\alpha \mathrm{GalCer}$ (Figure $3, \mathrm{~A}$ and $\mathrm{B})$, directly demonstrating that $\alpha \mathrm{GalCer-pretreated}$ $i$ NKT cells can be activated via the TCR. Similar data were obtained with an anti-Nur77 antibody (data not shown). However, as the intensity of the GFP expression was slightly lower for $\alpha \mathrm{GalCer}-$ pretreated $i \mathrm{NKT}$ cells, the results suggest that the induction of Nur77 downstream of the TCR might be slightly weaker or delayed in the $\alpha \mathrm{GalCer}$-pretreated $i \mathrm{NKT}$ cells compared with that in controls. When $\alpha$ GalCer-pretreated $i$ NKT cells expressing Nur77 $7^{\text {GFP }}$ at high and intermediate levels were compared, however, we observed no consistent phenotypic differences (data not shown).

Direct probing of early TCR signaling events in $i$ NKT cells by Western blot analysis is not practical due to the low cell numbers that can be recovered. Alternatively, we previously used single-cell analysis by flow cytometry via phospho-specific antibodies with $i$ NKT cell hybridomas (21). We now successfully adapted the protocol and measured the phosphorylation of ERK1/2 following TCR stimulation in primary $i$ NKT cells. As shown in Figure 3C, 2 minutes after $\alpha \mathrm{CD} 3 \varepsilon$-mediated stimulation, the phosphorylation of ERK1/2 (p-ERK1/2) was identical between control $i$ NKT cells and $\alpha \mathrm{Gal}-$ Cer-pretreated $i$ NKT cells. These data demonstrate that the MAPK pathway is fully functional in $\alpha$ GalCer-pretreated $i \mathrm{NKT}$ cells.

The 3 hallmarks of anergic $\mathrm{T}$ cells are the lack of proliferation, the lack of effector functions, and the inhibition of the MAPK pathways (15). By contrast, our data clearly demonstrate that $\alpha$ GalCer-pretreated $i$ NKT cells exhibit none of these features, and therefore contrary to current thinking, these cells are not anergic.

Cytokines activate aGalCer-pretreated iNKT cells. Besides antigen-driven TCR activation, most $i$ NKT cells can be additionally stimulated in a TCR-independent fashion to produce IFN- $\gamma$ by cytokines, such as IL-12 together with IL-18, which are produced by antigen-presenting cells (APCs) following stimulation with TLR ligands $(22,23)$. We therefore tested whether $\alpha \mathrm{GalCer}$-pretreated $i \mathrm{NKT}$ cells would respond to cytokines from activated innate immune cells triggered by TLR ligands. To this end, we injected LPS into control and $\alpha$ GalCer-pretreated mice and analyzed the response of $i$ NKT cells 6 hours later. Following LPS injection, the increased expression of CD69 (Figure 4A) and the production of IFN- $\gamma$ by $\alpha \mathrm{GalCer-}$ pretreated $i \mathrm{NKT}$ cells were comparable to what was observed in wild-type controls (Figure 4B), indicating that the response of $\alpha \mathrm{Gal}-$ Cer-pretreated $i$ NKT cells to TLR-stimulated APCs was unaltered. These data are in line with a previous report showing that $\alpha \mathrm{Gal}-$ Cer-pretreated $i$ NKT cells could respond to IL-12/IL-18 stimulation in vitro with IFN- $\gamma$ production, albeit with reduced intensity (12). 

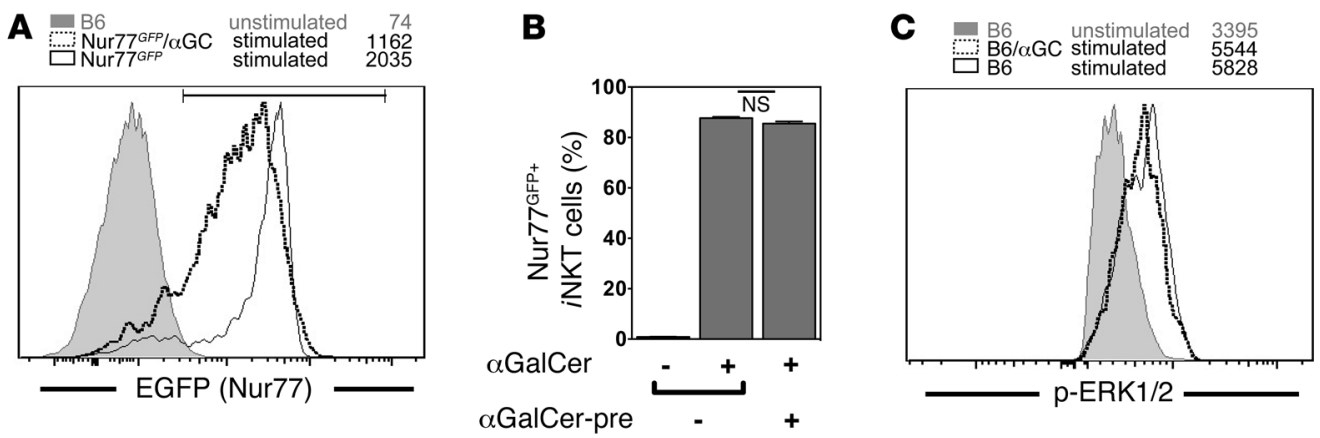

Figure 3. Effective TCR signaling of $\alpha$ GalCer-pretreated iNKT cells. (A and B) Control Nur $77^{\text {CFP }}$ mice and Nur $77^{\text {CFP }}$ mice

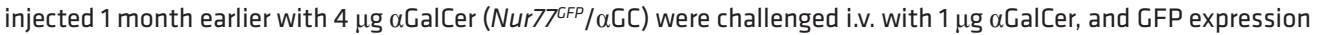
by splenic $i$ NKT cells was analyzed 1 hour later. Representative data (A) and a summary graph of the GFP+ ${ }^{+}$cells (B) are shown. $\alpha$ CalCer-pre, $\alpha$ GalCer pretreatment. Expression levels of unstimulated iNKT cells from C57BL/6 (B6) mice are shown in $\mathbf{A}$ as a negative control. (C) Enriched splenocytes from control congenic [57BL/6 mice (CD45.1 $)$ and from C57BL/6 mice (CD45.2+) injected 1 month earlier with $4 \mu \mathrm{g} \alpha$ GalCer (B6/ $\alpha \mathrm{CC})$ were mixed and stimulated by cross-linking with $\alpha \mathrm{CD} 3 \varepsilon$ antibodies. Two minutes later, cells were fixed, and the expression of p-ERK $1 / 2$ by indicated $i N K T$ cells was analyzed. Numbers in the histograms denote the geometric mean values for the depicted antigen in iNKT cells. Representative data from at least 2 independent experiments are shown in each panel.

waited another 2 weeks, and rechallenged the mice with $\alpha$ GalCer to analyze the TCRmediated response of $i \mathrm{NKT}$ cells (see experimental outline in Supplemental Figure 2). Pretreatment with LPS did not reverse the phenotype of $\alpha$ GalCer-pretreated $i$ NKT cell hyporesponsiveness to TCR stimulation, as measured by their proinflammatory cytokine response and their cellsurface phenotype (Figure 4C and data not shown).

These data indicate that $\alpha$ GalCer-pretreated $i \mathrm{NKT}$ cells retain the capacity to respond to stimuli provided by APC-derived cytokines. However, this type of stimu-

It has been reported that IL-2 provided in vitro can overcome the hyporesponsive phenotype of $\alpha \mathrm{GalCer-pretreated} i \mathrm{NKT}$ cells (9). Therefore, it could be argued that IL-2 or some other cytokine induced by LPS restored the response of $\alpha \mathrm{GalCer}$-pretreated $i$ NKT cells to LPS. To determine whether LPS could overcome the hyporesponsiveness of $\alpha \mathrm{GalCer}$-pretreated $i \mathrm{NKT}$ cells, we injected LPS into mice that had been injected with $\alpha$ GalCer 4 weeks earlier,

\section{Table 1. Summary of the changes observed on induced NIT10 cells}

\begin{tabular}{|c|c|c|}
\hline \multicolumn{3}{|c|}{ Downregulated (on induced NKT10 cells): } \\
\hline $\mathrm{CD} 25$ & CD127 & CD314 (NKG2D) \\
\hline CD47 & CD160 & GITR \\
\hline CD69 & CD186 (CXCR6) & NK1.1 \\
\hline $\operatorname{CD94}$ & CD192 (CCR2) & NKG2A/C/E \\
\hline CD122 & CD199 (CCR9) & \\
\hline \multicolumn{3}{|c|}{ Upregulated (on induced NKT10 cells): } \\
\hline CD4 & CD185 (CXCR5) & KLRG1 \\
\hline $\operatorname{CD} 5$ & $\mathrm{CD} 200$ & Ly49E \\
\hline $\operatorname{CD} 29$ & CD244 (2B4) & Ly49G2 \\
\hline CD31 & CD272 (BTLA) & Ly49I \\
\hline CD49d & CD278 (ICOS) & NRP1 (CD304) \\
\hline CD150 (SLAM) & CD279 (PD-1) & SLAMF6/Ly108 \\
\hline CD152 (CTLA4) & $\beta_{7}$-integrin & V $\alpha 14 i$ TCR \\
\hline \multirow[t]{2}{*}{ CD166 } & FR4 & \\
\hline & Unchanged: & \\
\hline CD11a & $\operatorname{CD93}$ & CD166 \\
\hline $\operatorname{CD} 22$ & $\operatorname{CD95}$ & CD335 (NKp46) \\
\hline $\mathrm{CD} 27$ & CD103 & Ly49A \\
\hline CD44 & CD210 (IL-10R) & \\
\hline CD62L & CD154 & \\
\hline
\end{tabular}

Expression levels of the indicated markers on iNKT cells from C57BL/6 control and C57BL/ 6 mice i.v. injected 1 month earlier with $4 \mu \mathrm{g} \alpha$ GalCer were compared. lation does not overcome the phenotype of hyporesponsiveness to subsequent TCR activation, consistent with the view that the LPSmediated activation is operating independently of the TCR (22).

The phenotype of aGalCer-pretreated iNKT cells is similar to that of Tregs. Having established that $\alpha \mathrm{GalCer}$-pretreated $i$ NKT cells can respond to TCR- and cytokine-mediated activation, we performed a detailed phenotypic characterization of $\alpha$ GalCer-pretreated $i$ NKT cells. A summary of the observed changes on $\alpha$ GalCer-pretreated $i$ NKT cells is provided in Table 1. $\alpha$ GalCer-pretreated $i$ NKT cells showed downregulated expression of NK1.1 and CD69 and increased expression of CD185 (CXCR5), CD278 (ICOS), and CD279 (PD-1) (Figure 5, A and B and Supplemental Figure 3, A-D). The expression of additional NK cell markers, namely, CD94, NKG2D, and NKG2A/C/E, was reduced on $\alpha$ GalCer-pretreated $i$ NKT cells as well (Supplemental Figure $3 \mathrm{~A})$. Other surface proteins that were expressed at lower levels on $\alpha$ GalCer-pretreated $i$ NKT cells included CD25, CD122, CD127, CD186(CXCR6), and CD199 (CCR9) (SupplementalFigure3,B-D). In contrast, besides the increased expression of CD279 (PD-1), $\alpha$ GalCer-pretreated $i$ NKT cells also displayed augmented expression of CD5, CD49d, CD150 (SLAM), CD200, CD244 (2B4), CD272 (BTLA), and SLAMF6/Ly108 (Figure 5, A and B, and Supplemental Figure 3, B-D). Of particular interest was the increased expression on $\alpha \mathrm{GalCer}$-pretreated $i \mathrm{NKT}$ cells of several markers, including CD152 (CTLA4), neuropilin-1 (NRP1), and FR4 (folate receptor 4), which have been associated with the inhibitory phenotype of Tregs (Figure 5, A and B). Whereas the relative percentage of $\mathrm{CD}^{+} \alpha \mathrm{GalCer}$-pretreated $i \mathrm{NKT}$ cells was largely unchanged, the expression levels of CD 4 increased on the $\mathrm{CD} 4^{+} \alpha \mathrm{GalCer}$-pretreated $i \mathrm{NKT}$ cells and approached the expression levels observed on conventional CD4 $4^{+} \mathrm{T}$ cells (Figure 5C and Supplemental Figure $4 \mathrm{~A}$ ). Expression of the TCR/CD $3 \varepsilon$ complex on $\alpha$ GalCer-pretreated $i$ NKT cells was increased slightly but consistently (Figure 5D and Supplemental Figure 4B). Furthermore, in contrast to control cells, $\alpha$ GalCer-pretreated $i$ NKT cells did not downregulate the $\mathrm{TCR} / \mathrm{CD} 3$ complex following activation with $\alpha \mathrm{GalCer}$, and there- 
A

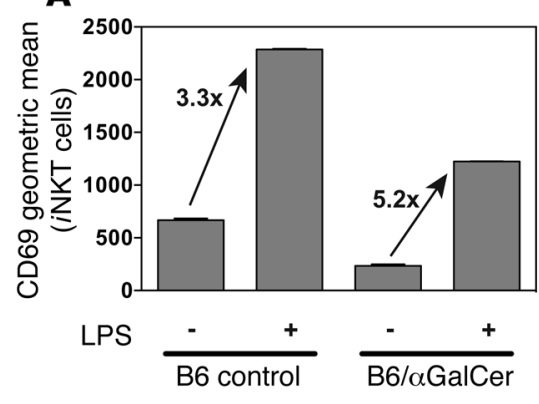

B

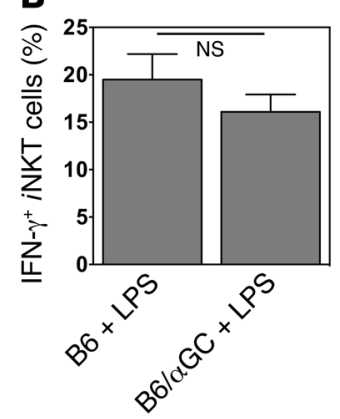

C

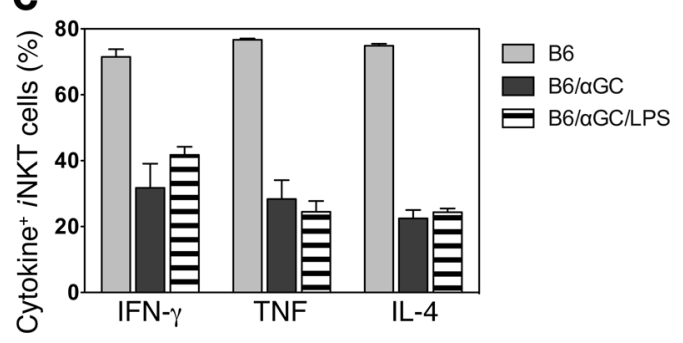

Figure 4. Cytokines activate $\alpha$ GalCer-pretreated $i$ NKT cells. (A and B) LPS (40 $\mu$ g) was i.v. injected, as indicated, into C57BL/6 control (B6) mice or mice i.v. injected 1 month earlier with $4 \mu \mathrm{g} \alpha \mathrm{GalCer}$ (B6/ $\alpha \mathrm{CC}$ ) (3 mice/group). Animals were sacrificed after 6 hours, and splenic iNKT cells were analyzed for CD69 expression ( $P<0.001$ for B6 vs. B6/ $\alpha$ GalCer; A), and IFN- $\gamma$ expression was measured by intracellular cytokine staining $(P=0.345$; B). Increase in CD69 expression based on geometric mean values. (C) $\alpha$ GalCer $(1 \mu \mathrm{g})$ was i.v. injected into wild-type mice (B6), mice i.v. injected 6 weeks earlier with $4 \mu \mathrm{g} \alpha \mathrm{GalCer}$ (B6 $\alpha \mathrm{GC}$ ), or mice i.v. injected 6 weeks earlier with $4 \mu \mathrm{g} \alpha$ GalCer and 2 weeks earlier with $40 \mu \mathrm{g}$ i.v. LPS (B6/ $\alpha \mathrm{CC}+\mathrm{LPS})(3 \mathrm{mice} / \mathrm{group})$. Splenic $i$ NKT cells were analyzed 90 minutes later by intracellular cytokine staining for production of the indicated cytokines. $P>0.5$ for B6/ $\alpha \mathrm{CC}$ versus B6/ $\alpha \mathrm{CC} / \mathrm{LPS}$ for all 3 cytokines. Experimental outline is depicted in Supplemental Figure 2. Representative data from at least 2 independent experiments are shown in each panel.

fore, the $\alpha$ GalCer-pretreated $i$ NKT cells could easily be detected 1 day after injection (Figure 5D and Supplemental Figure 4B). This indicates that the internalization and recycling of the TCR differs between $\alpha$ GalCer-pretreated and control $i$ NKT cells. Whereas several of the above changes were reported previously $(9,12,24-26)$, this is, to our knowledge, the most comprehensive investigation of $\alpha$ GalCer-pretreated $i$ NKT cells to date.

The results of the genome-wide gene expression of untreated and $\alpha$ GalCer-pretreated $i$ NKT cells were in good agreement with the flow cytometric data (Supplemental Figure 3). A set of 18 genes has been defined to be characteristically increased in expression by anergic T cells $(27,28)$. Importantly, from these 18 anergy-associated genes, only Egr 2 was changed in the $\alpha$ GalCer-pretreated $i$ NKT cells in a fashion similar to that seen in anergic T cells (Supplemental Figure $3 \mathrm{E}$ ), supporting the conclusion that $\alpha \mathrm{GalCer}$-pretreated $i$ NKT cells are not similar to anergic conventional T lymphocytes.

$\alpha$ GalCer-pretreated iNKT cells produce IL-10. Expression of CD152 (CTLA4), CD272 (BTLA), CD279 (PD-1), NRP1, and FR4 by $\mathrm{T}$ lymphocytes has been shown to be involved in regulatory and/ or tolerogenic contexts (29). Therefore, we determined whether $\alpha$ GalCer-pretreated $i$ NKT cells change their cytokine expression profile in a similar manner from that of a pro- to an antiinflammatory pattern. As described previously $(9,10), \alpha$ GalCer-pretreated $i$ NKT cells produced reduced amounts of IL- 4 and IFN- $\gamma$ following a secondary stimulation with $\alpha$ GalCer (Figure $6 \mathrm{~A}$ ), and the response was biased toward Th1 cytokines (Supplemental Figure 5). Similarly, the production of TNF, IL-13, and GM-CSF was decreased in the $\alpha$ GalCer-pretreated $i$ NKT cells (Figure $6, \mathrm{~A}$ and $\mathrm{B}$ ). However, when we measured IL-10 by intracellular staining, we found that up to $10 \%$ of $\alpha \mathrm{GalCer}$-pretreated $i$ NKT cells were IL$10^{+}$after secondary antigen stimulation (Figure 6, A and B). To broadly detect cells with the capacity to produce IL-10, we analyzed IL-10 reporter mice, in which an internal ribosome entry site and the gene for the fluorochrome EGFP were inserted into the Il1O locus ( $I l 1 O^{G F P}$, Vert-X) to faithfully label IL-10+ cells (30). Since GFP is a stable protein with a half-life of approximately 26 hours in cells (31) and since it is not secreted in this reporter strain, it accumulates over time and provides increased sensitivity for the detection of IL- $10^{+}$cells. However, because the kinetics of GFP induction is slower than that of the IL-10 protein (data not shown), we performed the analysis 16 hours after $\alpha \mathrm{GalCer}$ injection. Approximately half of the $\alpha$ GalCer-pretreated $i$ NKT cells were IL-10 ${ }^{\mathrm{GFP}+}$ following a second stimulation with $\alpha \mathrm{GalCer}(50.03 \% \pm$ $1.51 \%$, Figure $6, \mathrm{C}$ and D). All of the cells expressing IL-10 protein detected by intracellular cytokine staining were within the $\mathrm{EGFP}^{+}$ cell population (Supplemental Figure 6). However, the production of IL-10 was not required to induce the phenotype of $\alpha \mathrm{GalCer}-$ pretreated $i \mathrm{NKT}$ cells, as $\alpha \mathrm{GalCer}$ pretreatment in $\mathrm{Il1O}^{-/-}$mice led to phenotypic and functional changes that were indistinguishable fromthoseinwild-typemice(SupplementalFigure7Aandrefs.9,32). In agreement with this, IL-10 could be detected by intracellular cytokine staining in $\alpha$ GalCer-pretreated $i$ NKT cells from IL-10 receptor-deficient mice after restimulation in vitro (Supplemental Figure 7B). These data corroborate the conclusion that IL-10 is not required for the observed changes in $i$ NKT cells previously exposed to $\alpha$ GalCer. To confirm secretion of IL-10, $i$ NKT cells from control and $\alpha$ GalCer-pretreated mice were stimulated in vitro, and IL-10 in the supernatant was measured by ELISA. In line with the intracellular cytokine staining, we found that $\alpha \mathrm{GalCer}$-pretreated $i$ NKT cells secreted large amounts of IL-10 (Figure 6E). Furthermore, the IL-10 cytokine staining results were corroborated by the results of cytokine mRNA from the microarray analysis (Supplemental Figure 3F). The microarray analysis also indicated increased amounts of Tgfb3 mRNA (Supplemental Figure 3F), which was verified by RT-PCR (data not shown).

Taken together, these data demonstrate that $\alpha$ GalCerpretreated $i$ NKT cells acquire a novel surface phenotype and the potential to produce a different cytokine pattern, including IL-10, which mediates immune suppression. Based on this capability, we propose the name "induced NKT10 cells."

NKT1O cells are a distinct $i N K T$ cell subset. In recent years, functional subsets of V $\alpha 14 i$ NKT cells have been defined that can be distinguished based on the expression of particular surface markers and/or transcription factors (33-35). We next investigated the 
A
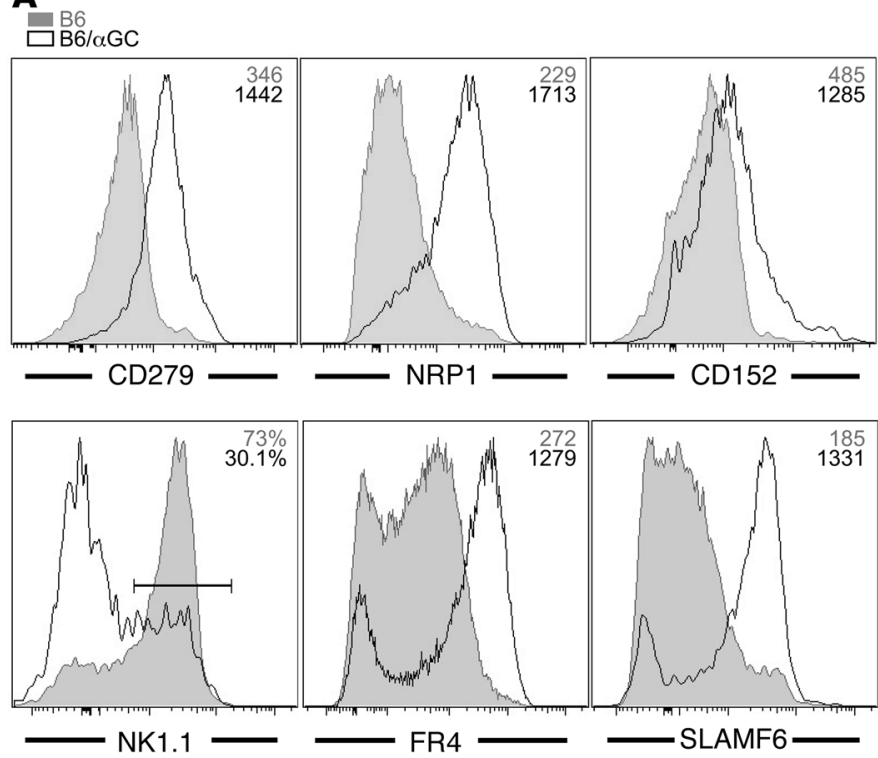

C

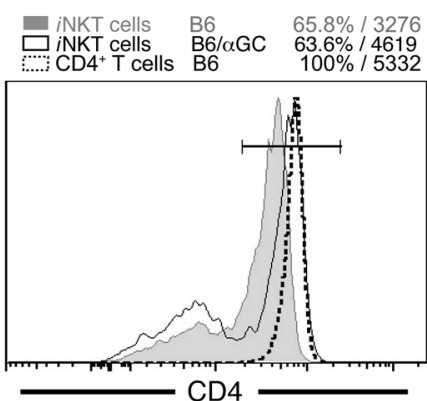

D

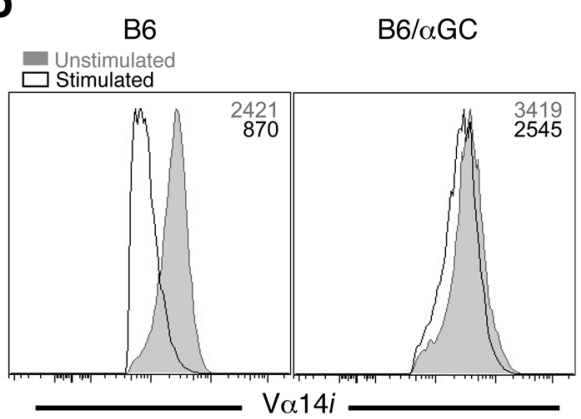

B
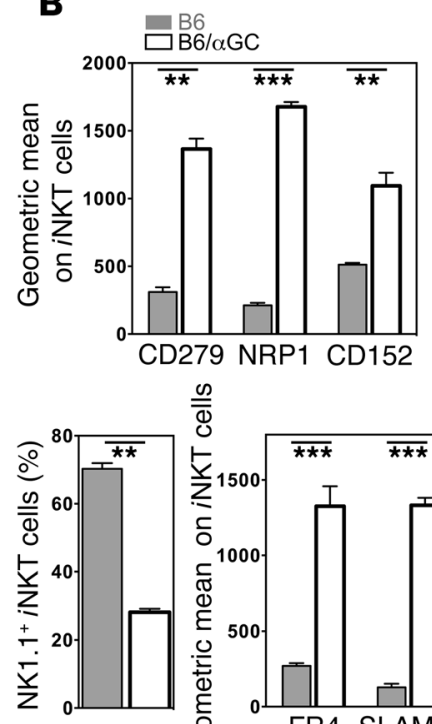

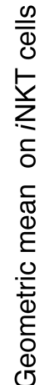

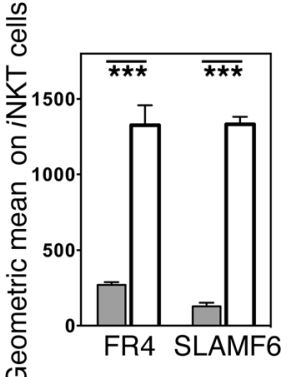

Figure 5. The phenotype of $\alpha$ GalCer-pretreated iNKT cells is similar to that of Tregs. (A and B) Splenic iNKT cells from C57BL/6 control (B6) or C57BL/6 mice injected 1 month earlier with $4 \mu \mathrm{g} \alpha \mathrm{GalCer}(\mathrm{B} 6 / \alpha \mathrm{CC})$ were stained for the indicated surface proteins. Representative data (A) and summary graphs (B) are shown. Numbers in the histograms denote either the geometric mean values or the percentage of positive cells within the depicted gate for the indicated antigens on iNKT cells from mice treated as shown. (C) Expression of CD4 on iNKT cells and CD4+ $\mathrm{T}$ cells from spleens from control B6 or $\mathrm{B} 6 / \alpha \mathrm{CC}$ mice. Numbers denote the percentage of CD4+ cells (left) and the geometric mean values for CD4 (right) on the cells within the gate depicted in the histogram. (D) Control B6 or B6/ $\alpha \mathrm{CC}$ mice were either left untreated (Unstimulated) or i.v. injected with $1 \mu \mathrm{g} \alpha \mathrm{GalCer}$ (Stimulated), and the expression of $V_{\alpha 14 i}$ TCR was measured on splenic iNKT cells with CD1d- $\alpha$ GalCer tetramers 16 hours later. Numbers in the histograms denote the geometric mean values for the indicated antigens on iNKT cells from mice treated as shown. Summary data for $\mathbf{C}$ and $\mathbf{D}$ are provided in Supplemental Figure 4, A and $\mathrm{B}$, respectively. Representative data from at least 3 independent experiments are shown in each panel. relation of NKT10 cells to published $i$ NKT cell subsets. The transcription factor FOXP3 is crucial for the function of Tregs (29), and its expression can be induced in $i$ NKT cells $(36,37)$. However, $\alpha$ GalCer-pretreated $i$ NKT cells did not express FOXP3 (Figure 7A). Furthermore, it has been reported that early after $\alpha$ GalCer injection (day 6), iNKT cells acquire a $\mathrm{T}$ follicular helper (Th) phenotype, characterized by the expression of the transcription factor BCL6 $(25,26,38)$. In agreement with these results, on day 6 after $\alpha \mathrm{GalCer}$ injection, we detected a population of BCL6 ${ }^{+} i$ NKT cells (Figure $7 \mathrm{~B}$ and Supplemental Figure 9). Furthermore, after 1 month, the $\alpha$ GalCer-pretreated $i$ NKT cells expressed several cell-surface molecules characteristic of NKTfh cells, such as CD185 (CXCR5) and SLAMF6, and they had increased Il21 mRNA expression (Supplemental Figure 3, C, D, and F). However, other evidence indicated that NKT10 cells are not NKTfh cells. First and most important, ity of NKT17 cells were CD4- and CD49d', whereas IL-10 ${ }^{+} i \mathrm{NKT}$ cells were largely $\mathrm{CD}_{4}{ }^{+}$and $\mathrm{CD} 49 \mathrm{~d}^{+}$(Figure 7, D and E). Additionally, in contrast to NKT17 cells (42), NKT10 cells did not express CD103 or CD196 (CCR6) (Supplemental Figure 3, B and C). These data demonstrate that NKT10 and NKT17 cells represent 2 independent $i \mathrm{NKT}$ cell subsets, despite the shared expression of NRP1 and the lack of NK1.1.

It has been reported that 1 month after $\alpha \mathrm{GalCer}$, the proinflammatory cytokine response of the $\alpha \mathrm{GalCer}$-pretreated $i \mathrm{NKT}$ cells partially recovered (9), suggesting that the NKT10 cell phenotype might be short lived as well. To gain a better understanding of the development of the $\alpha \mathrm{GalCer-induced} \mathrm{changes,} \mathrm{we} \mathrm{con-}$ ducted time-course experiments for up to 3 months after $\alpha \mathrm{GalCer}$ injection. Several markers associated with NKTfh cells, like BCL6 and CD127, changed rapidly but largely reverted 2-3 weeks af- 

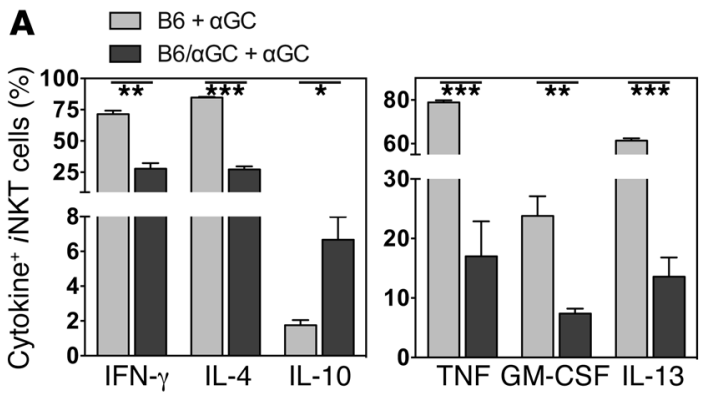

B

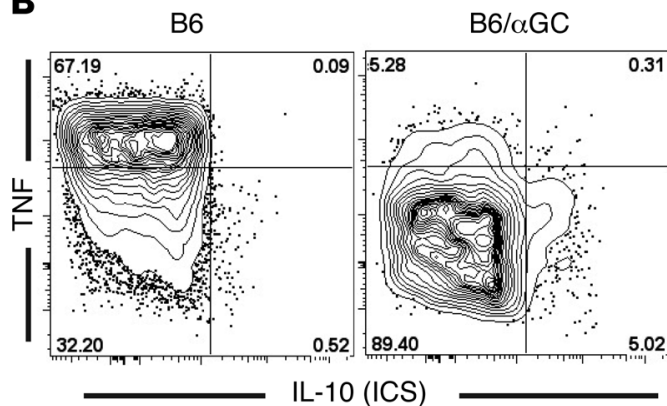

C

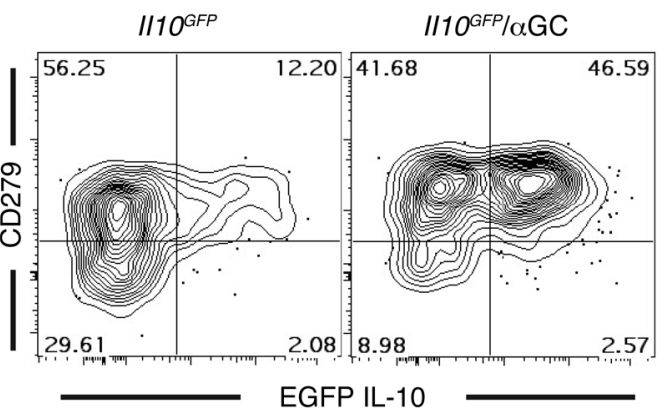

D
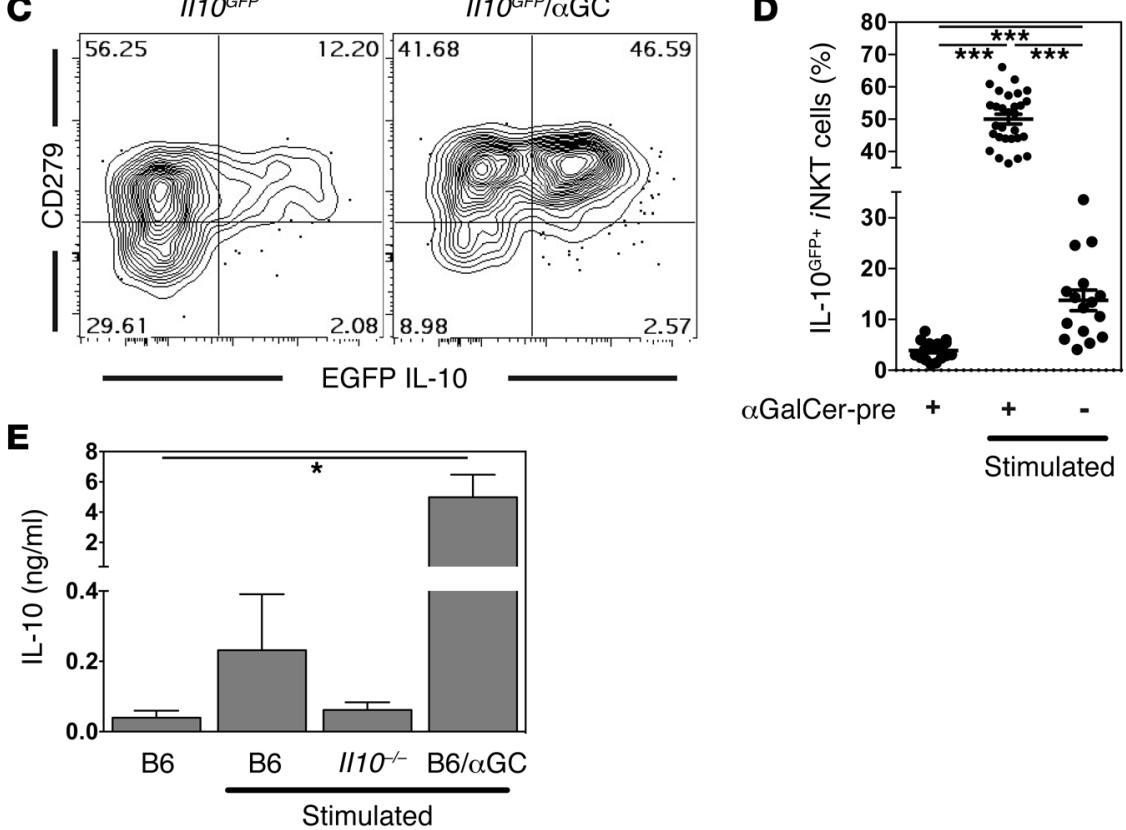

Figure 6. $\alpha$ GalCer-pretreated $i$ NKT cells produce IL-10. (A and B) $\alpha$ GalCer $(1 \mu \mathrm{g})$ was i.v. injected into wild-type (B6) or mice i.v. injected 1 month earlier with $4 \mu \mathrm{g} \alpha \mathrm{GalCer}$ (B6/ $\alpha \mathrm{GC}$ ) (3 mice/group). Splenic iNKT cells were analyzed 90 minutes later by intracellular staining for expression of the indicated cytokines. (A) Summary graph. Data in the 2 panels are derived from 2 independent experiments. (B) Representative flow cytometric data. ICS, intracellular cytokine staining. (C and D) Control II10 CFP mice or I/10 CFP mice given $4 \mu \mathrm{g} \alpha$ GalCer 1 month earlier (I/10 CFP $/ \alpha \mathrm{CC}$; $\alpha$ CalCer-pre) were either left untreated or were i.v. injected with $1 \mu \mathrm{g} \alpha$ GalCer (Stimulated), and splenic iNKT cells were analyzed 16 hours later for EGFP and CD279 (PD1) expression. Representative data (C) and a summary graph of IL-10 ${ }^{\mathrm{CFP}}$ expression (D) are shown. $\alpha$ GalCer-pre, unstimulated $=$ mean: $3.92 \% \pm 0.47 \%$; median: $3.61 \%$. $\alpha$ CalCer-pre, stimulated $=$ mean: $50.03 \% \pm 1.51 \%$; median: $51.71 \%$. Control, stimulated = mean: $13.76 \% \pm 2.04 \%$; median: $12.85 \%$. Data shown in $\mathbf{D}$ are from at least 8 independent experiments with at least 16 mice per group. Background values for IL-10 detection by intracellular staining or EGFP are shown and discussed in Supplemental

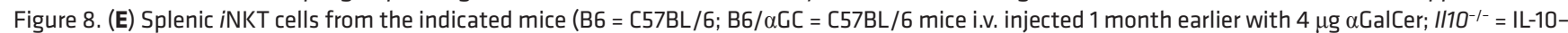
deficient mice) were sorted and were either left untreated or were stimulated in vitro for 4 days on $\alpha$ TCR $\beta$ antibody-coated plates before supernatants were collected and IL-10 levels were determined by ELISA. Representative data from 3 independent experiments are shown.

ter $\alpha$ GalCer injection (Supplemental Figure 10B). The phenotype of $\alpha$ GalCer-pretreated $i$ NKT cells then remained stable for up to 3 months (Supplemental Figure 10), and data derived 2 or 3 months after $\alpha \mathrm{GalCer}$ injection were largely indistinguishable from those from the 1-month time point. At later time points, the phenotype of $i \mathrm{NKT}$ cells appeared to slowly revert, but this was likely due to RTEs, as indicated by preliminary experiments with thymectomized mice (data not shown). These data suggest that $\alpha$ GalCer-pretreated $i$ NKT cells might recover full activity, but that this takes at least 4 months and is probably overshadowed by the appearance of "fresh" RTE $i$ NKT cells. As these RTE $i$ NKT cells have not been exposed to $\alpha \mathrm{GalCer}$, their response should be comparable to that of $i$ NKT cells in untreated control mice. Therefore, to exclude the involvement of RTE $i$ NKT cells, we performed ex- periments within 2 months of $\alpha \mathrm{GalCer}$ injection. Together, these data indicate that NKT1O cells are a defined $i$ NKT cell subset that is stable for at least 3 months.

IL-10-dependent immune regulation by induced NKT1O cells. The phenotype of induced NKT10 cells, with some similarity to Tregs, and their ability to produce IL-10, suggested that they are capable of regulating immune responses. Two in vivo models were used to test this hypothesis.

First, we observed that $\alpha$ GalCer-pretreated animals challenged with B16 melanoma cells suffered from a significantly higher tumor burden when treated concomitantly with $\alpha \mathrm{GalCer}$ (Figure 8A, bar 3 versus 4). This finding suggests that TCR-mediated activation of induced NKT1O cells was actively dampening the antitumor response, and therefore we reasoned that the 
A iNKT cells contro $\square$ iNKT cells $\alpha$ GalCer-pre $\quad 959$ FOX: CD25+ CD4+ T cells control

C

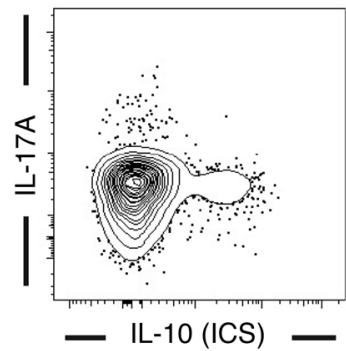

D $I L-10^{+} i$ NKT cells

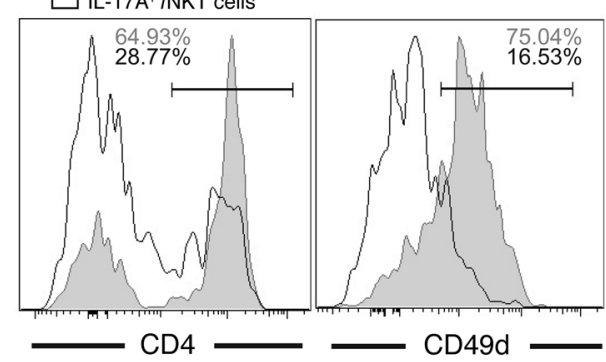

B

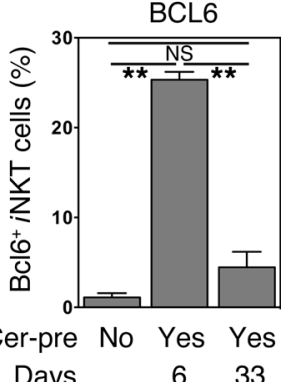

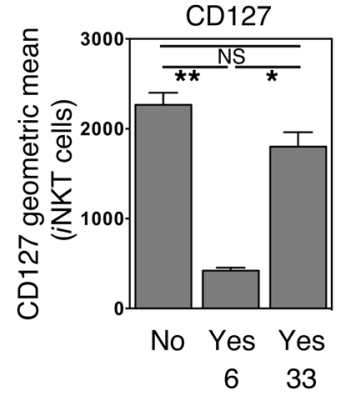

E

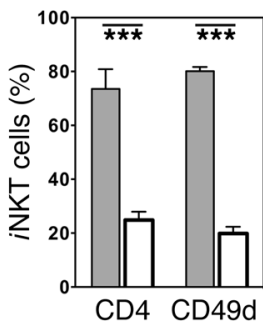

Figure 7. NIKT10 cells are a distinct iNKT cell subset. (A) Splenocytes from C57BL/6 control or C57BL/6 mice i.v. injected 1 month earlier with $4 \mu \mathrm{g} \alpha \mathrm{GalCer}$ ( $\alpha$ GalCer-pre) were stained for FOXP3 expression. Cells depicted are gated spleen $i$ NKT cells (live TCR $\beta^{+}$CD19-CD8 $\alpha^{-}$CD1d- $\alpha$ CalCer tetramer ${ }^{+}$) or spleen CD4+CD25+ T cells (live TCR $\beta^{+}$CD19-CD8 $\alpha^{-}$) from mice treated in the indicated manner. (B) Expression of BCL6 in (left panel) or CD127 on (right panel) splenic iNKT cells from C57BL/ 6 control ( $\alpha$ GalCer-pre: No) or C57BL/ 6 mice i.v. injected 6 days or 33 days earlier with $4 \mu \mathrm{g}$ $\alpha$ GalCer ( $\alpha$ GalCer-pre: Yes). Representative data are shown in Supplemental Figure 9. (C-E) C57BL/6 control (B6) or C57BL/6 mice injected 4-6 weeks earlier with $4 \mu \mathrm{g} \alpha$ GalCer (B6/ $\alpha \mathrm{CC}$ ) were rechallenged with $1 \mu \mathrm{g} \alpha \mathrm{GaICer}$ injected i.v., and 90 minutes later splenocytes were purified and incubated for 2 hours in vitro in the presence of protein transport inhibitors. Expression levels of IL-10 and IL-17A (C) or CD4 and CD49d (D and E) were then determined on iNKT cells. Representative data (D) and a summary graph (E) are shown. Numbers in the histograms in $\mathbf{D}$ denote the percentage of positive cells within the depicted gate. Representative data from at least 3 independent experiments are shown.

To address the role of induced NKT10 cell-derived IL-10, we transferred $i \mathrm{NKT}$ cells from wild-type and $I l 10^{-/-}$ mice into $i \mathrm{NKT}$ cell-deficient Ja18 ${ }^{-/-}$hosts. As noted above, IL-10 is not required for the generation of induced NKT10 cells (Supplemental Figure 7). The recipient host mice were then immunized with myelin oligodendrocyte glycoprotein peptide $\left(\mathrm{MOG}_{33-55}\right)$ and treated 3 times with $\alpha \mathrm{GalCer}$ (see experimental outline in Supplemental Figure 11). In agreement with previous results, mice with $i$ NKT cells treated multiple times with $\alpha$ GalCer were protected from EAE compared with mice without $i$ NKT cells (Figure 8B). Importantly, $J \alpha 18^{-/-}$host mice that received wild-type $i$ NKT cells displayed significantly ameliorated signs of disease progression compared with $J \alpha 18^{-/-}$host mice that received $I l 10^{-/-} i \mathrm{NKT}$ cells (Figure 8B).

Taken together, these data from 2 experimental systems demonstrate that IL-10 pro-

$\alpha$ GalCer-induced IL-10 production by induced NKT10 cells may act to promote tumor growth. Indeed, $\alpha$ GalCer-pretreated $I l 1 O^{-/-}$ mice displayed no difference in the amount of B16 tumor nodules following a secondary $\alpha$ GalCer challenge than did control mice (Figure 8A, bars 7 and 8 versus bars 3 and 4). These data are consistent with the hypothesis that induced NKT10 cells promote tumor growth in vivo via the production of IL-10. Interestingly, whereas the injection of $\alpha$ GalCer into $\alpha$ GalCer-pretreated animals had no effect on tumor growth when the mice were challenged with B16-CD1d (Figure 2D), it led to increased tumor burden when the mice were challenged with B16 (Figure 8A). These data suggest that the binding of $\alpha \mathrm{GalCer}$ to the B16-CD1d cells in vivo led to cognate recognition and the direct cytotoxic elimination of some of the tumor cells by the $\alpha$ GalCer-pretreated iNKT cells, in line with previous observations (16).

As a second in vivo model, representing an autoimmune disease, we analyzed the impact of induced NKT10 cells on the development of experimental autoimmune encephalomyelitis (EAE). EAE is a mouse model of multiple sclerosis, whereby immunization of mice with myelin-derived proteins leads to an autoimmune-mediated demyelination of axonal tracks, resulting in a progressive paralysis (43). It has been shown that repetitive injection of $\alpha$ GalCer can protect mice against EAE (44-47). Importantly, a single injection of $\alpha \mathrm{GalCer}$ did not protect mice against EAE in most $(45,48,49)$, albeit not all $(45,50)$, reports. duction by induced NKT10 cells can significantly impact the immune response.

NKT10 cells are a naturally occurring subset. Although NKT10 cells can be induced by $\alpha$ GalCer treatment, this antigen provides an extremely strong stimulus that may not be typical. Therefore, we determined whether a similar $i$ NKT cell subset could also be found in unchallenged mice. We injected $\alpha \mathrm{GalCer}$ into naive C57BL/6 mice and analyzed the production of IL-10 by intracellular staining 90 minutes later. We detected a small population of $\mathrm{IL}^{-10^{+}} i \mathrm{NKT}$ cells $(0.45 \% \pm 0.03 \%)$ in the spleen (Figure 9, A and B). To more inclusively capture $i \mathrm{NKT}$ cells capable of producing IL-10, we stimulated splenocytes with PMA and ionomycin for 4 hours in vitro. On average $1.77 \% \pm 0.18 \%$ of $i \mathrm{NKT}$ cells were $\mathrm{IL}-10^{+}$following this treatment (Figure 9, A and B). In analyzing the surface phenotype of these IL-10 ${ }^{+} i \mathrm{NKT}$ cells, we defined antigens that most clearly mark naturally occurring NKT10 cells as those that either were or were not expressed by at least $66 \%$ of the IL-10+ $i$ NKT cells and that additionally showed at least a 3-fold difference in increased or decreased frequency than was detected on the IL-10- $i$ NKT cells. According to these criteria, naturally occurring NKT10 cells were characterized by the relative lack of expression of NK1.1 and the expression of NRP1 and SLAMF6 (Figure 9C). Furthermore, additional antigens that correlated with $\mathrm{IL}-10^{+} i \mathrm{NKT}$ cells were defined as antigens 
A

B16
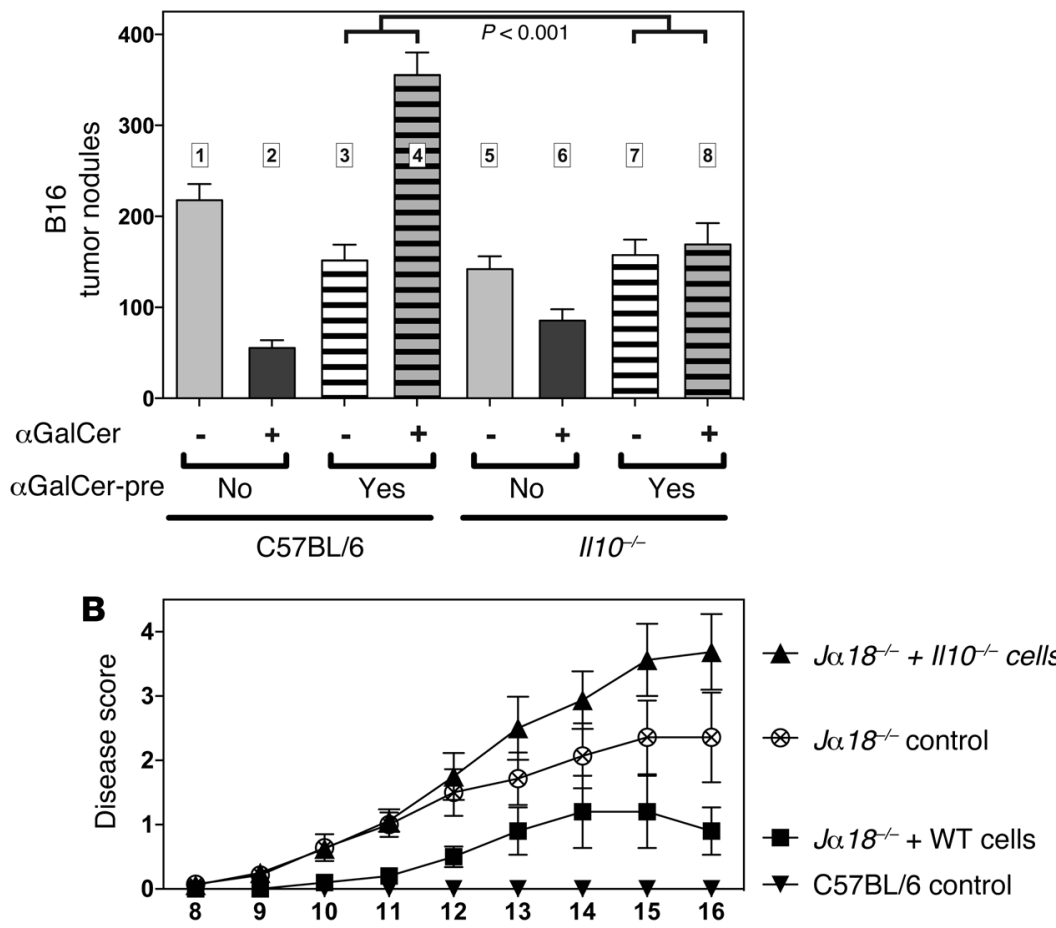

Figure 8. IL-10-dependent immune regulation by induced NKT10 cells. (A) C57BL/6 and $\| 110^{-1-}$ mice, either untreated ( $\alpha$ GalCer-pre: No) or injected 1 month earlier with $4 \mu \mathrm{g} \alpha \mathrm{GalCer}$ ( $\alpha$ GalCer-pre: Yes), were i.v. injected with $1 \times 10^{5}$ B16 melanoma cells. The indicated mice were additionally challenged i.v. 3 times (days 0,4 , and 7 ) with $1 \mu \mathrm{g} \alpha$ GalCer ( $\alpha$ GalCer: + ). Fourteen days later, the number of metastatic nodules in the lung was counted. $P<0.001$ for bars 3 and 4 versus bars 7 and 8 . Graph summarizes the results from 4 independent experiments with at least 15 mice per group. (B) $J \alpha 18^{-/-}$mice left untreated $\left(J \alpha 18^{-/-}\right.$control) or injected with $5 \times 10^{6}$ splenic $i$ NKT cells enriched from either C57BL/6 (Ja18 ${ }^{-1-}+$ WT cells) or $/ 110^{-1-}$ mice

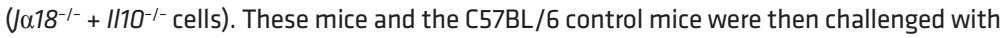
MOG-CFA and pertussis toxin to induce EAE. Furthermore, all mice were treated 3 times i.v. with $\alpha$ GalCer (days 0,4 , and 7 ), and disease progression was scored on the indicated days (5-8 mice/group). Experimental outline is depicted in Supplemental Figure 11. The difference between groups was significant $(P<0.05)$ on the following days: $J \alpha 18^{-1-}$ control versus $J \alpha 18^{-/-}+$WT cells $=$day 10 onward (except days 13 and 14 ); $/ \alpha 18^{-1-}+$ WT cells versus $J \alpha 18^{-1-}+1110^{-1-}$ cells $=$ day 10 onward. Data shown are representative of 2 independent experiments.

that were expressed at least 3 times more frequently on the $\mathrm{IL}-10^{+}$than on the IL-10- $i \mathrm{NKT}$ cells. Accordingly, IL-10 expression correlated with the expression of CD49d, CD200, CD278 (ICOS), CD279 (PD1), and FR4 (Figure 9C). We observed no correlation for CD4, CD44, CD69, CD127, and CD150 (data not shown). Furthermore, IL-10 $i$ NKT cells did not express CD314 (NKG2D), Ly49I, $\beta_{7}$-integrin, or IL-17A (data not shown). Importantly, all the antigens that marked or correlated with these naturally occurring NKT10 cells were similarly expressed by $\alpha \mathrm{Gal}-$ Cer-pretreated $i$ NKT cells, as discussed above and as indicated in Figure 5, Supplemental Figure 3, and Table 1.

Analysis of $I l 1 O^{G F P}$ reporter mice, together with our observation that NKT10 cells do not downregulate their TCR/CD3 complex after stimulation (see Figure 5D and Supplemental Figure $4 \mathrm{~B}$ ), offered us an alternative approach to quantify $i \mathrm{NKT}$ cells capable of producing IL-10 in previously untreated mice. Sixteen hours after a primary $\alpha \mathrm{GalCer}$ challenge, there was a decrease of approximately $97 \%$ in the number of the CD1d- $\alpha$ GalCer tetramer ${ }^{+} i \mathrm{NKT}$ cells detectable in the spleen (Figure 10B).
The number of $i$ NKT cells in the liver declined similarly (data not shown). This is likely due to downregulation of TCR expression $(51,52)$, although activation-induced cell death and migration of $i$ NKT cells may also contribute to this decline. Importantly, $17.0 \% \pm 1.3 \%$ of the remaining CD1d- $\alpha$ GalCer tetramer ${ }^{+} i$ NKT cells expressed IL-10 ${ }^{\text {GFP }}$ (Figure 10, A and B). This represented $0.53 \% \pm 0.08 \%$ compared with the starting $i$ NKT cell population in the spleen (Figure 10B), which was in good agreement with the values derived from the intracellular IL-10 staining (Figure 9, A and B). For some other $i$ NKT cell subsets, preferential homing to specific organs, such as the lymph nodes for NKT17 cells, has been reported (42). The recent suggestion of the presence of antiinflammatory $i$ NKT cells in white adipose tissue (WAT) (53-55) and the regulatory phenotype of induced NKT10 cells we described above made the subcutaneous white adipose tissue (scWAT) a candidate tissue for preferential localization of NKT10 cells. Additionally, we observed that scWAT $i$ NKT cells were enriched for the expression of markers also expressed by induced NKT10 cells (Figure 10, $\mathrm{C}$ and $\mathrm{D})$. Therefore, we enumerated naturally occurring NKT10 cells in the scWAT of $I l 10^{\text {GFP }}$ reporter mice, as we did for the spleen. Following primary stimulation with $\alpha$ GalCer, a significantly higher percentage of $i$ NKT cells remained detectable in scWAT compared with that in the spleen (Figure 10B). Importantly, $31.6 \% \pm 3.6 \%$ of the $i$ NKT cells recovered from the scWAT-expressed IL-10 ${ }^{\text {GPP }}$ (Figure 10, A and B). Considering that nearly $50 \%$ of the scWAT $i$ NKT cells were still detectable 16 hours after injection, these IL-10 ${ }^{\mathrm{GFP}+}$ $i$ NKT cells represented $13.5 \% \pm 2.6 \%$ of the starting population of $i$ NKT cells in the scWAT (Figure 10B). Therefore, NKT10 cells are enriched, or become enriched rapidly following antigenic exposure, in the WAT. Based on these data, we propose that such $\mathrm{IL}^{-10^{+}} i \mathrm{NKT}$ cells in unchallenged mice represent a naturally present $i$ NKT cell subset. We refer to these IL-10-producing $i$ NKT cells in mice not exposed to $\alpha$ GalCer as "natural NKT10 cells," without claiming that they originate exclusively in the thymus or as a result of peripheral stimulation.

Given that we could detect natural NKT10 cells in unchallenged control mice, we tested whether NKT10 cells could also be found in human PBMCs. To this end, human PBMCs from healthy donors were stimulated with PMA and ionomycin for 4 hours. This stimulation yielded a clear IL-10 signal from V $\alpha 24 i$ NKT cells by intracellular cytokine staining (Figure 11A). Similar to the findings with mouse splenocytes, the percentage of $\mathrm{IL}^{-10^{+}} i \mathrm{NKT}$ cells was mostly below $2 \%$ (mean: $0.42 \% \pm 0.08 \%$; median: $0.38 \%$ ), but NKT10 cells could be detected in 19 of 20 donors tested (Figure 11B).

Together, these data demonstrate that NKT1O cells are a distinct and novel $i$ NKT cell subset in mice and humans that occurs naturally in the absence of $\alpha \mathrm{GalCer}$ exposure. 

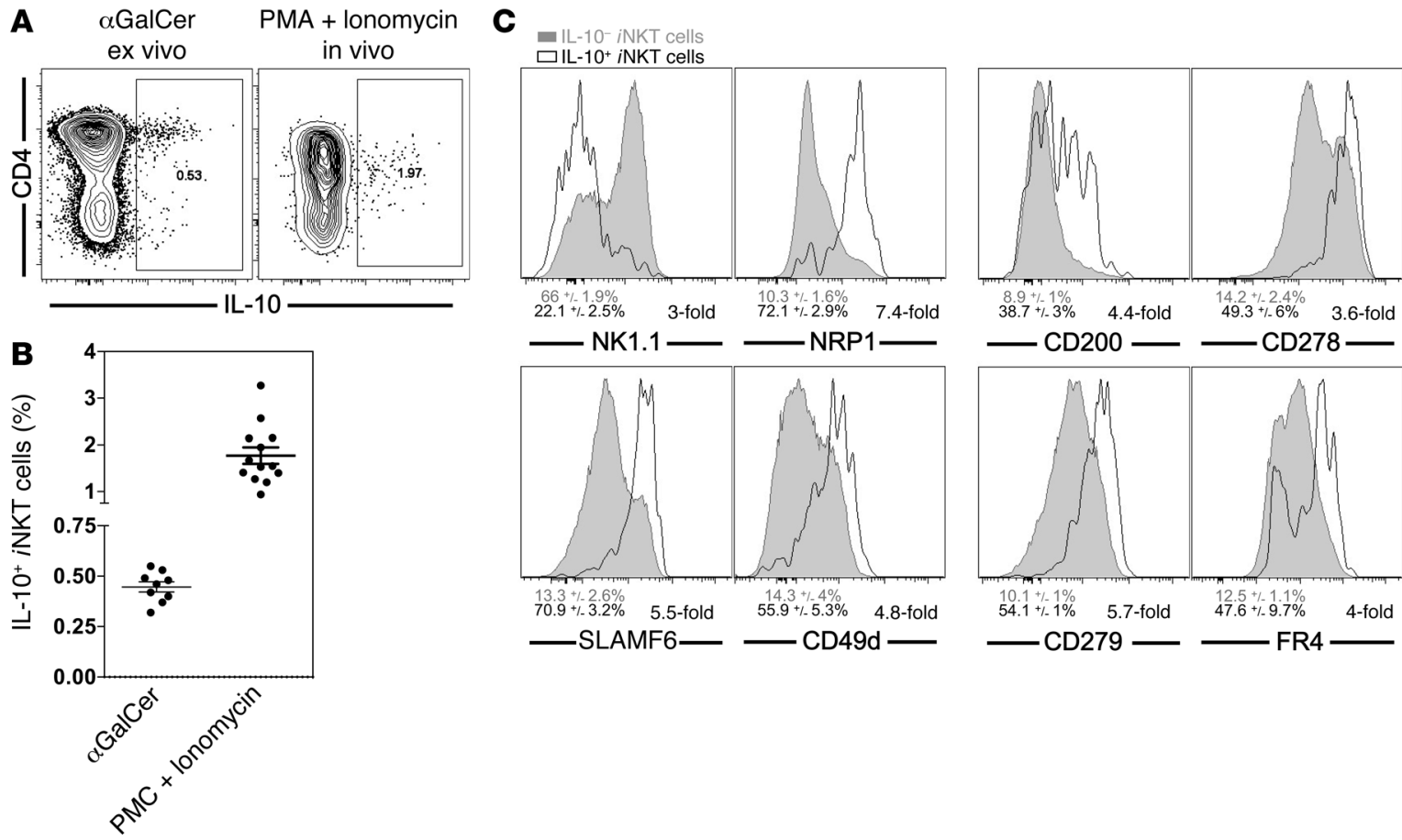

Figure 9. A subset of untreated Va14i NIKT cells express IL-10. (A and B) C57BL/6 mice were left untreated or were injected with $1 \mu \mathrm{g} \alpha \mathrm{C}$ alCer, and 90 minutes later, splenocytes were purified and incubated for 2 hours in vitro in the presence of protein transport inhibitors before iNKT cells were analyzed ( $\alpha$ GalCer). Alternatively, splenocytes were stimulated with PMA and ionomycin in vitro for 4 hours (PMA + ionomycin). Representative data (A) and a summary graph (B) are shown. Data in $\mathbf{B}$ are summarized from at least 4 independent experiments with at least 9 mice per group. $\alpha \mathrm{GalCer}=$ mean: $0.45 \% \pm 0.03 \%$; median: $0.46 \%$. PMA + ionomycin = mean: $1.77 \% \pm 0.18 \%$; median: $1.55 \%$. Numbers in the dot plots denote the percentage of cells in the respective rectangle. Gating is based on $0 \%$ of IL- $10^{+}$cells in unstimulated $\mathrm{C57BL} / 6$ iNKT cells. Similar background values were obtained with isotype control antibody or by staining of stimulated $1 / 10^{-1-}$ iNKT cells (Supplemental Figure 8). (C) Splenocytes from C57BL/6 mice were stimulated with PMA and ionomycin as described in $\mathbf{A}$, and $i N K T$ cells were stained for IL-10 and the indicated markers. Histograms depict the overlay of IL-10- (gray) and IL-10+ (black) iNKT cells for the indicated markers. Numbers below the graphs represent either the average expression of the indicated marker on IL-10- (gray) and IL-10+ (black) iNKT cells (left), or the fold difference between both of these values (right). All differences were statistically significant $(P<0.01)$. Data shown are representative of 3 to 6 independent experiments.

\section{Discussion}

Here, we describe a novel $i$ NKT cell subset, which we have termed NKT10 cells, that is characterized both by the expression of several proteins found on Tregs and by the capacity to produce IL-10 after antigenic stimulation. Importantly, NKT10 cells occur naturally in mice and in humans, albeit at a low frequency, and they expand greatly after activation with the strong agonist $\alpha$ GalCer. Such $\alpha$ GalCer-induced NKT10 cells were not anergic, as previously suggested, but retained their cytotoxic activity and their response to TCR-dependent and TCR-independent stimulation by cytokines from APCs. Furthermore, through the production of IL-10, induced NKT10 cells were able to modulate the tumor load of B16 melanoma-challenged mice and the outcome of EAE. Therefore, our data reveal new aspects of $i$ NKT cell functional diversity.

Treatment of $i$ NKT cells with $\alpha$ GalCer in vivo has been proposed to lead to a general hyporesponsive state similar to that of anergy, based on reduced antigen-induced proliferation and production of IFN- $\gamma$ and IL-4 following restimulation. However, the original data in support of this hypothesis analyzed the splenic $i$ NKT cell response at the cell population level after in vitro culture $(9,10)$. Given that the relative percentage of $\alpha \mathrm{GalCer}$-pretreated $i$ NKT cells is significantly lower in the spleen of $\alpha$ GalCerpretreated mice (Figure 2A and Supplemental Figure 10A), such an approach could underestimate the per-cell response of $i \mathrm{NKT}$ cells. Furthermore, the in vitro response of $\alpha \mathrm{GalCer}$-pretreated $i$ NKT cells does not necessarily reflect their in vivo response. Therefore, to gain insight into the per-cell response of $i$ NKT cells from $\alpha$ GalCer-pretreated mice, we used single-cell flow cytometric assays to directly measure $i \mathrm{NKT}$ cell activity ex vivo. This is not typically done, although a few reports have analyzed the $i \mathrm{NKT}$ cell cytokine response on a single-cell level in vitro (12) or in vivo $(12,56)$. Using our approach, we confirmed the reduced production of proinflammatory cytokines by $\alpha$ GalCer-pretreated $i \mathrm{NKT}$ cells (Figure 6, A and B). In contrast, while it was reported that the expansion of $\alpha \mathrm{GalCer}$-pretreated $i$ NKT cells after a secondary stimulation with $\alpha$ GalCer was reduced $(12,56)$, their steady-state proliferation in vivo, as measured by Ki67 and BrdU staining, was actually increased (Figure 1), suggesting an increased response to homeostatic signals from cytokines or self-antigen.

The induction of GFP in $\alpha$ GalCer-pretreated $i$ NKT cells from Nur $77^{G F P}$ reporter mice, following antigen reexposure, showed productive TCR signaling, albeit reduced from controls (Figure 3, $A$ and $B)$. The induction of Nur77 is downstream of Ras activation, which is defective in anergic T cells $(27,28)$. Staining for $\mathrm{p}-\mathrm{ERK} 1 / 2$ following TCR stimulation in primary $i$ NKT cells (Figure 3C) directly demonstrated unimpaired TCR-induced MAPK signaling 

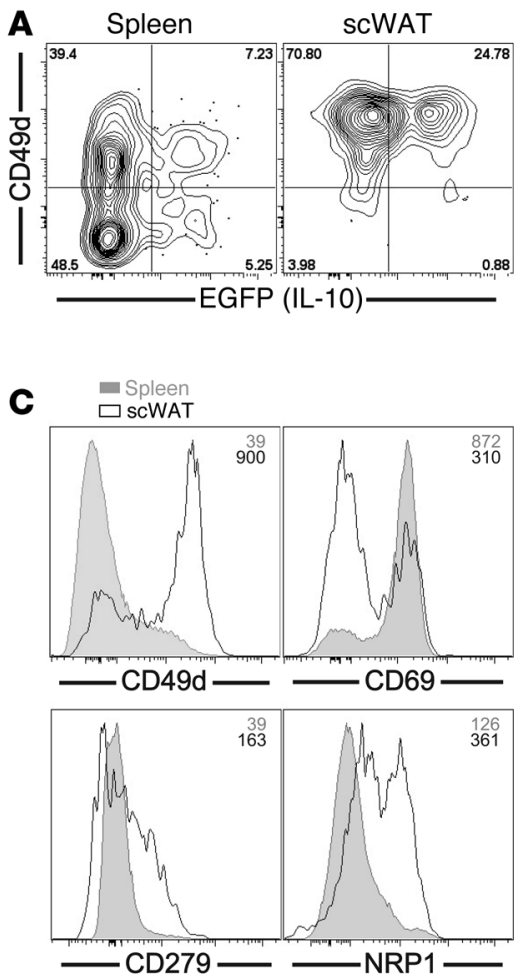

B
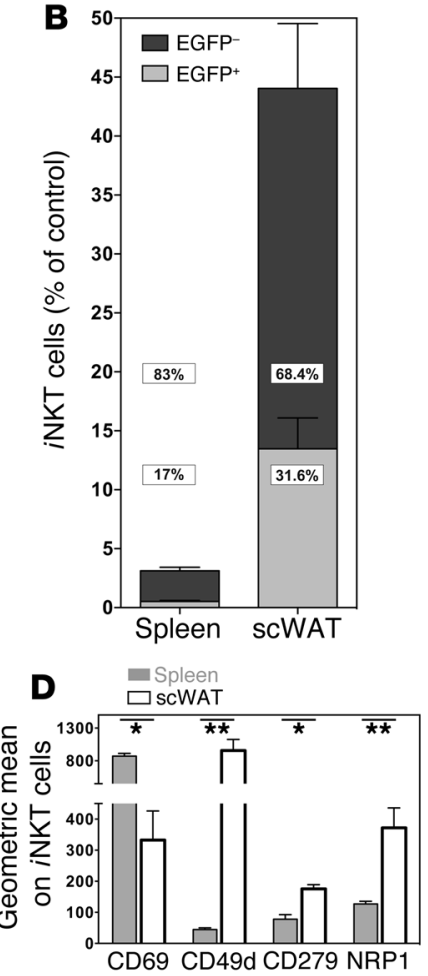

Figure 10. NKT10 cells are enriched in WAT. (A and B) I/10 CFP mice were left untreated or were i.v. injected with $1 \mu \mathrm{g} \alpha \mathrm{GalCer}$, and $i$ NKT cells in spleen and scWAT were analyzed 16 hours later. (A) Expression of EGFP and CD49d from 1 representative experiment. Numbers in the dot plots denote the percentage of cells in the respective quadrants. (B) Percentage of EGFP+ (light gray) and EGFP- (dark gray) iNKT cells from spleen and scWAT was calculated as the percentage of $i$ NKT cells in untreated control mice. $P<0.001$ for spleen versus scWAT for all comparisons. Graph summarizes data from 4 independent experiments with 13 mice per group. (C and D) iNKT cells from spleen and scWAT of C57BL/6 mice were analyzed for expression of the indicated markers. Representative data (C) and a summary graph (D) are shown. Numbers in the histograms in C denote the geometric mean values for the depicted antigens on iNKT cells. Representative data from 1 of at least 3 independent experiments are shown.

existing $i$ NKT cell nomenclature, here we define NKT10 cells as the $i$ NKT cell subset capable of producing IL-10 as one of its predominant cytokines and demonstrate that these NKT10 cells are distinct from the other known $i$ NKT cell subsets (Figure 7). Dynamic changes occur in the $i$ NKT cell population after $\alpha \mathrm{GalCer}$ treatment, including the transient appearance of a Tfh-like phenotype of $i \mathrm{NKT}$ cells (NKTfh cells) in the spleen that is characterized by expression of the transcription factor BCL6 $(25,26)$. Consistent with this, while BCL6 is expressed in $i$ NKT cells on day 6 after $\alpha$ GalCer injection, it declines thereafter (Figof $\alpha \mathrm{GalCer-pretreated} i \mathrm{NKT}$ cells. Furthermore, the results from the microarray analysis indicated that expression of most of the genes associated with the anergic state $(27,28)$ was not increased in aGalCer-pretreated iNKT cells (Supplemental Figure 3E). Together, our data clearly demonstrate that $\alpha \mathrm{GalCer}$-pretreated $i$ NKT cells are not anergic.

We therefore tested the responsiveness of $\alpha \mathrm{GalCer}$-pretreated $i$ NKT cells by 3 additional readouts. First, when we analyzed $\alpha$ GalCer-specific in vivo cytotoxicity (16), hyporesponsiveness was not observed (Figure 2A). We obtained similar results in thymectomized animals, indicating that RTEs could not account for the cytotoxicity (Figure 2A). Second, we activated $\alpha$ GalCer-pretreated $i$ NKT cells via TLR ligand-induced cytokines from APCs, and their response was comparable to that of control cells in this context as well (Figure 4, A and B). Third, aGalCer-pretreated $i$ NKT cells displayed an increased production of IL-10 (Figure 6). Whereas the term anergy implies the absence of an $i$ NKT cell response, our data demonstrate that $\alpha \mathrm{GalCer}$ pretreatment leads instead to modulation of the $i \mathrm{NKT}$ cell response.

In recent years, functional subsets of $i \mathrm{NKT}$ cells have been defined. Some, such as NKT1 and NKT2 (33-35), NKT17 (39-42), and IL17RB $^{+} i$ NKT (57) cells, originate predominantly in the thymus, while others, such as NKTfh $(25,26,38)$ and FOXP3 ${ }^{+} i \operatorname{NKT}(36,37)$ cells, arise after immunization. The definition of $i$ NKT cell subsets is largely based on their expression of transcription factors and their function, especially significant biases in cytokine production of the respective iNKT cell types. NKT1, NKT2, and NKT17 cells are defined as the $i$ NKT cell subset biased toward Th1, Th2, or Th17 cytokines, respectively. Like their Th subset counterparts, these $i$ NKT cell subsets also produce several cytokines in addition to the signature one(s) that define the subsets. In line with the ure 7B, Supplemental Figure 9, and Supplemental Figure 10B). However, NKT10 cells did not express FOXP3, BCL6, or IL-17A after stimulation, and thus by choosing the 1-month time point for most of our experiments, we were able to exclude the involvement of NKTfh cells as well as limit the contribution of RTE $i$ NKT cells.

The relationship of NKTfh to NKT10 cells remains to be determined. Our data indicated that NKT10 cells expand after $\alpha \mathrm{GalCer}$ treatment in vivo. This is not specific to $\alpha \mathrm{GalCer}$ stimulation, however, since repeated injection (3 times) of a weaker antigen also caused an increase in this cell population (data not shown). Additionally, $\alpha$ GalCer stimulation does not always lead to the generation of induced NKT1O cells, as we did not observe this, in line with previous reports $(9,10)$, when we injected bone marrow-derived DCs loaded with $\alpha$ GalCer (data not shown). However, whether the expansion of NKT10 cells after $\alpha \mathrm{GalCer}$ is the result of selective expansion of a preexisting population of NKT10 cells or of conversion to the NKT10 cell phenotype cannot be answered definitively at this point. When we sorted NRP1- $i$ NKT cells, transferred them into Ja18 ${ }^{-/}$mice, and injected $\alpha \mathrm{GalCer}$, we could detect a rapid increase in NKT10 cells (data not shown), consistent with induction of these cells. However, even though sorting NRP1- $i$ NKT cells likely excluded naturally occurring NKT10 cells, the presence of a small amount of contaminating cells cannot be ruled out. Nonetheless, we favor the idea that some non-NKT1O cells can convert into NKT10 cells following aGalCer stimulation. Furthermore, it is not known whether those $i$ NKT cells capable of producing IL-10 in the absence of $\alpha$ GalCer pretreatment are natural, in the sense that they differentiated in the thymus, or whether they are induced in the periphery, possibly by chronic antigenic exposure. A role of NK1.1 $1^{+}$T cell-derived IL-10, in the absence of previous $\alpha \mathrm{GalCer}$ exposure, has so far only been reported in the systemic 
A

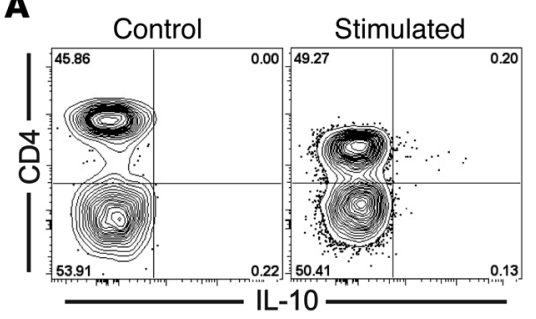

B

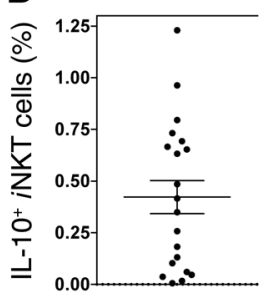

Figure 11. A subset of V $\alpha 24 i$ NKT cells express IL-10. PBMCs from healthy human donors were stimulated with PMA and ionomycin in vitro for 4 hours in the presence of protein transport inhibitors before iNKT cells were analyzed for the indicated markers. (A) Expression of IL-10 and CD4 from 1 representative experiment. Numbers in the dot plots denote the percentage of cells in the respective quadrants. Representative data from 1 of at least 3 independent experiments are shown. (B) Summary graph of the percentage of IL-10+ $\mathrm{V} \alpha 24 i \mathrm{NKT}$ cells (mean: $0.42 \% \pm 0.08 \%$; median: $0.38 \%$ ). Graph summarizes the results from 6 independent experiments with a total of 20 donors.

tolerance mouse model of anterior chamber-associated immune deviation (ACAID) (58). Therefore, it is intriguing to speculate that NKT10 cells are important for the maintenance of tolerance in immune-privileged sites.

Besides the altered phenotype and the production of IL-10, we found that a surprising feature of NKT10 cells was their lack of downregulation of the TCR/CD3 complex following $\alpha$ GalCer stimulation (Figure 5D and Supplemental Figure 4B). This lack of TCR/CD3 complex downregulation, together with the use of the $I l 1 O^{G F P}$ reporter mice, allowed us to estimate the number of natural NKT10 cells in the spleen and scWAT. We detected $0.53 \% \pm 0.08 \%$ NKT10 cells in the spleen, taken as a ratio of the CD1d- $\alpha$ GalCer tetramer ${ }^{+} \mathrm{GFP}^{+}$cells after $\alpha \mathrm{GalCer}$ stimulation to the number detected in the starting cell population. The ratio analysis, however, assumes that in the relatively short 16-hour time span, there was negligible NKT10 cell division, migration, or activation-induced cell death, and that this time point is too early for significant conversion to NKT10 cells. However, the values obtained with the $I l 1 O^{G F P}$ reporter mice were in good agreement with the percentage of IL-10 ${ }^{+} i \mathrm{NKT}$ cells 90 minutes after $\alpha$ GalCer $(0.45 \% \pm 0.03 \%)$. The percentage of IL- $10^{+} i \mathrm{NKT}$ cells after stimulation with PMA and ionomycin was significantly higher $(1.77 \% \pm 0.18 \%)$, which may be a more accurate reflection of the potential of cells to produce this cytokine, since an antigenic stimulation in vivo rarely captures $100 \%$ of the cells able to respond. Furthermore, phenotypic analysis at steady state and analysis of the $I l 10^{G F P}$ reporter mice (Figure 10) demonstrated that NKT10 cells were greatly enriched in the scWAT $(13.5 \% \pm 2.6 \%)$. Recent reports have demonstrated that the frequency of $i \mathrm{NKT}$ cells is reduced in the adipose tissue of obese mice (53-55) and in the omentum of obese patients compared with the frequency of these cells in lean controls (59). Adipose tissue-resident $i$ NKT cells displayed an antiinflammatory phenotype $(55,60)$, and $\alpha$ GalCer injection into obese mice caused weight loss and improved metabolic health (55). In light of these reports, our finding that NKT10 cells are enriched in scWAT (Figure 10) suggests that natural NKT10 cells present in scWAT may help to maintain healthy adipose tissue.

EAE is a mouse model of multiple sclerosis, in which $i \mathrm{NKT}$ cells influence the disease course $(44-46,61)$. It has been shown that repetitive injection of $\alpha \mathrm{GalCer}$ can protect mice against EAE (44-47). Importantly, a single injection of $\alpha \mathrm{GalCer}$ did not protect mice against EAE according to most (45, 48-50), albeit not all $(45,50)$, reports. Differences were attributed to the genetic background, the route and timing of application, and the dosage of $\alpha \mathrm{GalCer}(45,46,50)$. The protection was originally thought to be due to a Th2 bias in the secondary response of $\alpha$ GalCer-pretreated $i$ NKT cells $(8,9,62,63)$. However, this conclusion was based on the analysis of the $\alpha \mathrm{GalCer}$ response on a cell population level, either from in vitro cultures $(8,9,62)$ or from analysis of sera (63). In contrast, when we analyzed the $\alpha \mathrm{GalCer}$ response of pretreated $i$ NKT cells on a single-cell level, either no bias or a Th1 cytokine bias was detected (Supplemental Figure 5 and refs. 12, 56, 63). The apparent discrepancy of the results is likely due to the lack of NK cell trans-activation following a secondary stimulation of $\alpha \mathrm{Gal}$ Cer-pretreated $i$ NKT cells (63). In regard to the $\alpha$ GalCer-induced EAE protection, however, is is not entirely clear which $i$ NKT cellderived cytokine is important. IL-4 and/or IL-10 have been suggested $(44,45,48,64-66)$, but some data contradict this $(46,61)$. Similarly, divergent results have been reported for IFN- $\gamma$ (pro: refs. 45, 46, 66, 67; con: ref. 64).

However, based on our data, we propose that the protection against EAE by repetitive $\alpha$ GalCer challenge depends on the requirement to first induce sufficient numbers of NKT10 cells and then to subsequently stimulate IL-10 production from them. The generation of cells with an NKT10 cell phenotype in this model does not require their ability to produce IL-10, but we noticed a worsening of disease in mice that received IL-10-deficient $i \mathrm{NKT}$ cells compared with the control $J \alpha 18^{-/-}$mice (Figure $8 \mathrm{~B}$ ). Therefore, it is possible that in the absence of the ability to produce IL-10, the proinflammatory cytokines still produced by $\alpha \mathrm{Gal}$ Cer-pretreated $i$ NKT cells can even exacerbate disease progression. In several other contexts, $i \mathrm{NKT}$ cells have been reported to regulate immune responses by inducing IL-10 production by other cells or to produce IL-10 themselves $(8,44,46,58,64,68-70)$. However, in these cases, a separate population of $i$ NKT cells with a unique phenotype was not described. Furthermore, it is also conceivable that NKT10 cells use additional regulatory mechanisms, such as the expression of CD152, CD200, CD279, NRP1, or TGF- $\beta$. Further studies in different contexts are required to determine the relative contributions of IL-10 and other factors to the regulation carried out by NKT10 cells.

The recent appreciation that $i \mathrm{NKT}$ cells are heterogeneous suggests that some of the controversies regarding the function of $i$ NKT cells could depend on which subset is activated. Our data indicate that $\alpha \mathrm{GalCer}$-induced NKT10 cells regulate concomitant adaptive immune responses. The fact that up to $13.5 \%$ of $i$ NKT cells in control mice and healthy human donors resembled $\alpha$ GalCer-pretreated $i$ NKT cells suggests that they represent a novel $i$ NKT cell subset. The characterization of suppressive NKT10 cells could help to resolve current controversies about the dichotomous nature of $i$ NKT cells observed in various studies, namely their ability to exert either pro- or antiinflammatory effects. Such knowledge also could be important for understanding the functional consequences of $\alpha \mathrm{GalCer}$ or other 
glycolipid antigens in therapy and how to deliberately tailor $i$ NKT cell responses for therapeutic applications.

\section{Methods}

Mice and cell lines. All mice were housed under specific pathogen-free conditions at the animal facilities of the La Jolla Institute for Allergy and Immunology (La Jolla, California, USA) in accordance with

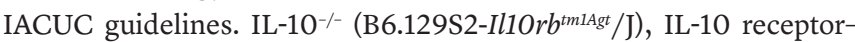

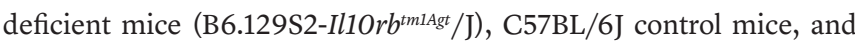
C57BL/6J mice thymectomized at 7 weeks of age were purchased from The Jackson Laboratory. B6.129-Tcra-J ${ }^{\text {tmitgi }}\left({\left.\mathrm{J} \alpha 18^{-/}\right)}^{-}\right.$mice, $\mathrm{Nr} 4 \mathrm{al}$ (Nur77 ${ }^{\mathrm{GFP}}(20)$ and $\mathrm{Il10}$ (IL-10 ${ }^{\mathrm{GFP}}$ ) (30) reporter mice on a C57BL/6 background were gifts of Masaru Taniguchi (RIKEN Institute, Yokohama, Japan), Kristin A. Hogquist (University of Minnesota, Minneapolis, Minnesota, USA), and Christopher L. Karp (Cincinnati Children's Hospital Medical Center, Cincinnati, Ohio, USA), respectively. The melanoma B16-F10 (C57BL/6, CRL-6475) cell lines were purchased from ATCC and were retrovirally transfected into stably expressed CD1d, as previously described (16).

Reagents and monoclonal antibodies. $\alpha \mathrm{GalCer}$ [(2S,3S,4R)-1-O-(a-D-galactopyranosyl)-N-hexacosanoyl-2-amino-1,3,4-octadecanetriol] was obtained from Kyowa Hakko Kirin Co. Ltd. (Tokyo Research Park, Tokyo, Japan). E. coli (0111-B4) LPS and BrdU were purchased from Sigma-Aldrich. 7-AAD was obtained from Invitrogen. The following monoclonal antibodies against mouse antigens were used: $\beta_{7}$-integrin (M293), BCL6 (K112-91), BrdU (3D4), CD3e (145.2C11, 17A2), CD4 (GK1.5, RM4-5), CD5 (537.3), CD8 $\alpha$ (53-6.7, 5H10), CD11a (2D7), CD19 (1D3, 6D5), CD25 (PC61.5), CD22 (OX-97), CD27 (LG.7F9), CD29 (Ha2/5), CD31 (390, MEC13.3), CD44 (IM7), CD45.1 (A20), CD45.2 (104), CD45R/ B220 (RA3-6B2), CD47 (miap301), CD49d (R1-2), CD62L (MEL14), CD69 (H1.2F3), CD93 (R139), CD94 (18d3), CD95 (Jo2), CD103 (2E7), CD107a (1D4B), CD107b (ABL-93), CD122 (TM-beta1), CD127 (A7R34, SB/199), CD150/SLAM (TC15-12F12.2), CD152/CTLA4 (14D3), CD154/CD40L (MR1), CD160 (BY55), CD166 (ALC48), CD185/CXCR5 (2G8), CD186/CXCR6 (TG3), CD192/CCR2 (48607), CD199/CCR9 (CW-1.2), CD200 (OX90), CD210/IL-10R (1B1.3a), CD244 (2B4), CD272/BTLA (6F7), CD278/ICOS (C398.4A), CD279/ PD-1 (J43, RMP1-30), FOXP3 (FJK-16s), FR4 (12A5), GFP (polyclonal), GITR (DTA-1), GM-CSF (MP1-22E9), IFN- $\gamma$ (XMG1.2), IL-2 (JES65H4), IL-4 (11B11, BVD6-24G2), IL-10 (JES5-16E3), IL-13 (13A), Ki67 (B56), KLRG1 (2F1), Ly49a (A1), Ly49a/e (D7), Ly49G2 (4D11), Ly49I (YLI-90), NK1.1 (PK136), NKG2A/C/E (20D5), NKG2D/CD314 (C7), NKp46/CD335 (29A1.4), NRP1/CD304 (polyclonal), Nur77 (12.14), p-ERK1/2 (E10), SLAMF6/Ly108 (330-AJ), TCR $\beta$ (H57-597), TNF (MP6-XT22), and TNP-KLH (A95-1). Monoclonal antibodies against the following human antigens were used in this study: CD3e (OKT3, HIT3a, UCHT1), CD4 (OKT4, S3.5, SK3), CD8 (3B5, RPA-T8, SK1), CD19 (HIB19, SJ25-C1), CD20 (2H7, PC61.5), CD25 (2A3), CD45RA (HI30, HI100), CD56 (HCD56), CD161 (HP-3G10), CD194/CCR4 (1G1), CD197/CCR7 (150503), FoxP3 (PCH101), IFN- $\gamma$ (4S.B3, B27), IL-4 (8D4-8), IL-10 (JES3-9D7), IL-17A (64DEC17), IgG1к isotype (eBRG1), TNF (MAb11), and V $\alpha 24 i$ (6B11). Antibodies were purchased from BD Biosciences, BioLegend, eBioscience, Invitrogen, R\&D Systems, or Santa Cruz Biotechnology Inc. Antibodies were biotinylated or conjugated with Pacific Blue, eFluor 450, V450, Brilliant Violet 421, Pacific Orange, V500, Brilliant Violet 570, Quantum Dot 605, Quan- tum Dot 655, eFluor 650, Brilliant Violet 650, Brilliant Violet 711, Brilliant Violet 785, Brilliant Violet 786, FITC, Alexa Fluor 488, PerCP, PerCP-Cy5.5, PerCP-eFluor 710, PE, PE-TexasRed, PE-CF594, PE-Cy5.5, PE-Cy7, APC, Alexa Fluor 647, eFluor 660, Alexa Fluor 700, APC-Cy7, or APC-eFluor 780. Anti-mouse CD16/32 antibody (2.4G2) used for Fc receptor blocking was isolated in our laboratory. FcR inhibitor for human cells was obtained from eBioscience. Unconjugated mouse and rat $\operatorname{IgG}$ antibodies were purchased from Jackson ImmunoResearch. Dead cells were labeled with a Blue, Aqua, or Yellow Dead Cell Stain Kit (Invitrogen).

In vivo challenge and cell preparation. In vivo cytotoxicity assays were performed as reported previously (16). In brief, splenic CD19+ B cells were either pulsed with $\alpha$ GalCer $(250 \mathrm{ng} / \mathrm{ml}, 1$ hour) or were mock treated, then differentially labeled with CFDA-SE (Invitrogen), and equal numbers $\left(5 \times 10^{6}\right)$ of both cell populations were i.v. injected

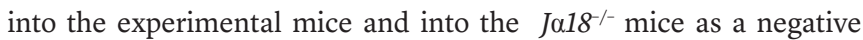
control. Four hours later, the presence of target cells in spleen was determined by flow cytometry, and the specific lysis was calculated as described (16). $i$ NKT cells were pretreated with $\alpha$ GalCer by i.v. injection of $4 \mu \mathrm{g} \alpha \mathrm{GalCer}$ and analyzed 4-6 weeks later or as otherwise indicated. Acute activation in vivo was induced by i.v. injection of $1 \mu \mathrm{g} \alpha \mathrm{GalCer}$ followed by analysis 90 minutes later or as otherwise indicated. For in vivo labeling with BrdU (Sigma-Aldrich), the indicated mice were injected i.p. with $1 \mathrm{mg}$ BrdU (in PBS), and at the same time, BrdU ( $1 \mathrm{mg} / \mathrm{ml})$ was placed in the drinking water supplemented with $5 \%$ glucose $(\mathrm{w} / \mathrm{v})$. Three days later, splenic $i$ NKT cells were analyzed for BrdU incorporation using a BrdU flow kit (BD Biosciences) according to the manufacturer's instructions.

Human PBMCs were isolated by use of Ficoll-Paque (GE Healthcare) density gradient centrifugation. Single-cell suspensions from mouse liver, spleen, and thymus were prepared as described (16). Mouse scWAT was minced, digested $(1 \mathrm{mg} / \mathrm{ml}$ collagenase type II and $8 \mu \mathrm{g} / \mathrm{ml}$ DNase I; both from Sigma-Aldrich) for 40 minutes $\left(37^{\circ} \mathrm{C}\right.$, $200 \mathrm{rpm}$ ) and filtered through a 70- $\mu \mathrm{m}$ cell strainer (BD Biosciences). In some experiments intended for intracellular staining of IL-10, splenocytes were purified by use of Lymphoprep (Axis-Shield) density gradient centrifugation and by depletion of B cells with antiCD45R-coated magnetic beads (Invitrogen). For enrichment of V $\alpha 14 i$ NKT cells from splenocytes, cells were incubated with biotin-conjugated antibodies for CD8 $\alpha$, CD11b, CD19, CD24, CD62L, CD45RA, F4/80, Ly6G/Gr1, and TER119, followed by negative selection with streptavidin magnetic beads (STEMCELL Technologies), resulting in cell suspensions containing $8 \%-15 \%$ iNKT cells.

Lung metastases with B16 melanoma cells. B16 and B16-CD1d melanoma cells were either loaded with $250 \mathrm{ng} / \mathrm{ml} \alpha \mathrm{GalCer}\left(37^{\circ} \mathrm{C}, 90 \mathrm{~min}-\right.$ utes) or mock treated, washed twice with PBS, and $1 \times 10^{5}$ tumor cells were i.v. injected into C57BL/6 mice as indicated in Figure 2D and Figure 8A. Fourteen days after challenge, the number of metastatic nodules on the lung surface was counted. Five hundred tumor nodules were established as the upper limit for counting, since at higher densities, discrete tumor nodules could not be accurately separated.

$E A E$. EAE was induced by immunization with $\mathrm{MOG}_{33-55}$ (MEVGWYRSPFSRVVHLYRNGK; Synthetic Biomolecules). $\mathrm{MOG}_{33-55}$ $(200 \mu \mathrm{g})$ was s.c. injected with a 25 -gauge needle in $0.1 \mathrm{ml}$ CFA (Sigma-Aldrich) into 3 to 4 different sites on the flank. Concomitant with the peptide and 2 days later, 200 ng pertussis toxin (Sigma-Aldrich) was injected i.v. on day 0 and i.p. on day 2. Disease was monitored daily 
from day 8 onward. Freshly isolated lymphocytes enriched for $i$ NKT cells (containing $5 \times 10^{6} i \mathrm{NKT}$ cells) were i.v. injected into mice shortly before the immunization. Disease was monitored visually using a 0-5 ranking $(0=$ normal, $0.5=$ tail weakness, $1=$ hind limb weakness, $2=$ mild hind limb paralysis, $3=$ moderate hind limb paralysis, 4 = complete hind limb paralysis, $5=$ moribund or dead). Gel packs were added to all cages as soon as mice reached a score above 2. Animals with a score of 4 were euthanized once they remained in this state for more than 2 consecutive days and were then categorized as score 5 .

In vitro cultures. For ex vivo experiments intended for intracellular staining of IL-10 or IL-17A, lymphocytes were cultured for 2 hours in medium consisting of RPMI 1640 (Invitrogen) supplemented with $10 \%$ (v/v) FCS and 1\% (v/v) Pen-Strep-Glutamine (10,000 U/ml penicillin, 10,000 g/ml streptomycin, $29.2 \mathrm{mg} / \mathrm{ml} \mathrm{L-glutamine;} \mathrm{Invitro-}$ gen) in the presence of GolgiPlug and GolgiStop (BD Biosciences) at $37^{\circ} \mathrm{C}$. Ex vivo stimulation was performed with PMA and ionomycin (both from Sigma-Aldrich) for 4 hours at $37^{\circ} \mathrm{C}$ in the presence of GolgiPlug and GolgiStop. For detection of degranulation, splenocytes from congenic control (CD45.1) and $\alpha \mathrm{GalCer-pretreated} \mathrm{animals} \mathrm{(CD45.2)}$ were incubated for 5 hours at $37^{\circ} \mathrm{C}$ at a $1: 1$ ratio in $\alpha \mathrm{CD} 3 \varepsilon$ antibodycoated $(5 \mu \mathrm{g} / \mathrm{ml}, 145.2 \mathrm{C} 11)$ plates in the presence of $0.5 \mu \mathrm{g} / \mathrm{ml}$ $\alpha \mathrm{CD} 107 \mathrm{a}-(1 \mathrm{D} 4 \mathrm{~B})$ and $\alpha \mathrm{CD} 107 \mathrm{~b}$ (ABL93) Alexa Fluor 488-labeled antibodies (Santa Cruz Biotechnology Inc.). For the measurement of p-ERK1/2, enriched splenocytes from congenic control (CD45.1) and $\alpha$ GalCer-pretreated animals (CD45.2) were mixed at a 1:2 ratio, incubated for 10 minutes on ice with $10 \mu \mathrm{g} / \mathrm{ml} \alpha \mathrm{CD} 3 \varepsilon$ antibody (145.2C11, BD Biosciences), then washed and stimulated with $40 \mu \mathrm{g} / \mathrm{ml}$ cross-linking anti-hamster IgG antibodies (G70-204 and G94-56; BD Biosciences) together with $\mathrm{CD} 1 \mathrm{~d}-\alpha \mathrm{GalCer}$ tetramers at $37^{\circ} \mathrm{C}$. After 2 minutes, cells were fixed and stained for p-ERK1/2. Staining of primary $i \mathrm{NKT}$ cells in this assay required the use of CD1d- $\alpha$ GalCer tetramer labeled with the fluorochrome BV421 (BD Biosciences), together with the stimulation and rapid addition of the fixation reagent after the 2 minutes incubation.

Flow cytometry and ELISA. Flow cytometry and preparation of fluorochrome-conjugated aGalCer-loaded CD1d tetramers were performed as previously described (71). Cell sorting was performed with a FACSAria cell sorter (BD Biosciences). $i$ NKT cells were defined throughout as live $\mathrm{CD} 8 \alpha^{-} \mathrm{CD} 19 / \mathrm{CD} 45 \mathrm{R}^{-} \mathrm{CD} 44^{+} \mathrm{TCR} / \mathrm{CD}^{+} \mathrm{C}-$ D1d- $\alpha$ GalCer tetramer ${ }^{+}$cells (mouse) or as live CD20-CD45RA-CD197- ${ }^{-}{ }^{+}{ }^{+} \mathrm{V} \alpha 24 i^{+}$(clone 6B11) cells (human). IL-10 levels in culture supernatants were determined by ELISA using BioLegend reagents, according to the manufacturer's recommendations.

RNA microarray. Enriched Va14i NKT cells (CD1d- $\alpha$ GalCer tetramer ${ }^{+} \mathrm{TCR}^{+}$) were isolated from spleen using a FACSAria cell sorter (BD Biosciences) and stored as cell pellets at $-80^{\circ} \mathrm{C}$. RNA was isolated from the frozen cell pellets using the RNeasy Mini Kit (QIAGEN), and transcripts were amplified with the Ovation RNA amplification system V2 (NuGEN) and purified with the QIAquick PCR purification kit (QIAGEN) according to the manufacturer's instructions. In vitro transcription (IVT) probe generation and hybridization to Affymetrix Mouse Genome 4302.0 arrays (Platform GPL1261) were performed at the Veterans Medical Research Foundation GeneChip Microarray facility (UCSD). Signal intensity data and lists of differentially expressed genes were compiled using VAMPIRE (Subramanian Laboratory, UCSD) and Genespring (Agilent) software. Microarray data were deposited in the NCBI's Gene Expression Omnibus (GEO GSE47959; http://www.ncbi.nlm.nih.gov/geo/query/acc.cgi?acc=GSE47959) (72).

Statistics. Results are expressed as the mean \pm SEM. Statistical comparisons were drawn using a 2-tailed Student's $t$ test (Excel; GraphPad Prism, GraphPad Software) for all paired samples or otherwise using an ANOVA test (GraphPad Prism). Normal distribution was validated by the D'Agostino-Pearson omnibus normality test (GraphPad Prism), either directly $(n>10)$ or after combining values from repetitive experiments. $P$ values less than 0.05 were considered statistically significant and are indicated as ${ }^{*} P<0.05,{ }^{* *} P<0.01$, and ${ }^{* *} P<0.001$ in the figures. Each experiment was repeated at least twice, and background values were subtracted. Graphs were generated with GraphPad Prism.

Study approval. Human PBMCs were obtained from healthy donors in accordance with the La Jolla Institute for Allergy and Immunology Normal Blood Donor Umbrella Program (VD-057). All mouse experiments were performed in an AAALAC-accredited facility with prior approval of the IACUC of the La Jolla Institute for Allergy and Immunology and in accordance with the US Public Health Service (PHS) Policy on Humane Care and Use of Laboratory Animals .

\section{Acknowledgments}

This work was funded by NIH grants RO1 AI45053, AI69296, and R37 AI71922 (to M. Kronenberg); R01 HL097368 (to C.C. Hedrick), and by an Outgoing International Fellowship from Marie Curie Actions (to G. Wingender). The authors wish to thank Archana Khurana, Iain Scott, and Tine Decruy for excellent technical assistance. We are grateful to Masaru Taniguchi, Kristin A. Hogquist, and Christopher L. Karp for providing mouse strains and to Hilde Cheroutre, Melvin Wei, Isharat Yusuf, Koen Venken, Dirk Elewaut, Aaron J. Tyznik, Isaac Engel, Barbara Sullivan, Grzegorz Chodaczek, Erika Naka, Stephanie Tangsombatvisit, and Bjoern Peters for their scientific contributions.

Address correspondence to: Mitchell Kronenberg or Gerhard Wingender, La Jolla Institute for Allergy and Immunology, 9420 Athena Circle, La Jolla, California 92037, USA. Phone: 858.752.6540; E-mail: mitch@liai.org (M. Kronenberg). Phone: 858.752.6738; E-mail: gwing@liai.org (G. Wingender).
1. Bendelac A, Savage PB, Teyton L. The biology of NKT cells. Annu Rev Immunol. 2007;25:297-336.

2. Kronenberg M, Gapin L. The unconventional lifestyle of NKT cells. Nat Rev Immunol. 2002;2(8):557-568.

3. Kronenberg M. Toward an understanding of NKT cell biology: progress and paradoxes. Annu Rev Immunol. 2005;23(1):877-900.

4. Godfrey DI, Kronenberg M. Going both ways: immune regulation via CD1d-dependent NKT cells. JClin Invest. 2004;114(10):1379-1388.

5. Wingender G, Kronenberg M. Role of NKT cells in the digestive system. IV. The role of canonical natural killer T cells in mucosal immunity and inflammation. Am J Physiol Gastrointest Liver Physiol. 2008;294(1):G1-G8.

6. Fujii S, et al. Adjuvant activity mediated by iNKT cells. Semin Immunol. 2010;22(2):97-102.

7. Cerundolo V, Silk JD, Masri SH, Salio M. Harnessing invariant NKT cells in vaccination strategies.
Nat Rev. 2009;9(1):28-38.

8. Burdin N, Brossay L, Kronenberg M. Immunization with alpha-galactosylceramide polarizes CD1-reactive NK T cells towards Th2 cytokine synthesis. Eur J Immunol. 1999;29(6):2014-2025.

9. Parekh VV, et al. Glycolipid antigen induces longterm natural killer $\mathrm{T}$ cell anergy in mice. JClin Invest. 2005;115(9):2572-2583.

10. Fujii S, Shimizu K, Kronenberg M, Steinman RM. Prolonged IFN- $\gamma$-producing NKT response 
induced with $\alpha$-galactosylceramide-loaded DCs. Nat Immunol. 2002;3(9):867-874.

11. Sullivan BA, Kronenberg M. Activation or anergy: NKT cells are stunned by alpha-galactosylceramide. J Clin Invest. 2005;115(9):2328-2329.

12. Uldrich AP, et al. NKT cell stimulation with glycolipid antigen in vivo: costimulation-dependent expansion, Bim-dependent contraction, and hyporesponsiveness to further antigenic challenge. JImmunol. 2005;175(5):3092-3101.

13. Scholzen T, Gerdes J. The Ki-67 protein: from the known and the unknown. J Cell Physiol. 2000;182(3):311-322.

14. Boussiotis VA, et al. p27kip1 functions as an anergy factor inhibiting interleukin 2 transcription and clonal expansion of alloreactive human and mouse helper T lymphocytes. Nat Med. 2000;6(3):290-297.

15. Schwartz RH. T cell anergy. Annu Rev Immunol. 2003;21(1):305-334.

16. Wingender G, Krebs P, Beutler B, Kronenberg M. Antigen-specific cytotoxicity by invariant NKT cells in vivo is CD95/CD178-dependent and is correlated with antigenic potency. JImmunol. 2010;185(5):2721-2729.

17. Betts M. Sensitive and viable identification of antigen-specific $\mathrm{CD}^{+} \mathrm{T}$ cells by a flow cytometric assay for degranulation. J Immunol Methods. 2003;281(1-2):65-78.

18. Smyth MJ, Crowe NY, Godfrey DI. NK cells and NKT cells collaborate in host protection from methylcholanthrene-induced fibrosarcoma. Int Immunol. 2001;13(4):459-463.

19. Smyth MJ, et al. Sequential production of interferon- $\gamma$ by NK1.1(+) T cells and natural killer cells is essential for the antimetastatic effect of $\alpha$-galactosylceramide. Blood. 2002;99(4):1259-1266.

20. Moran AE, et al. T cell receptor signal strength in Treg and iNKT cell development demonstrated by a novel fluorescent reporter mouse. JExp Med. 2011;208(6):1279-1289.

21. Sullivan BA, et al. Mechanisms for glycolipid antigen-driven cytokine polarization by $\mathrm{V} \alpha 14 \mathrm{i}$ NKT cells. J Immunol. 2010;184(1):141-153.

22. Nagarajan NA, Kronenberg M. Invariant NKT cells amplify the innate immune response to lipopolysaccharide. Jimmunol. 2007;178(5):2706-2713.

23. Tyznik AJ, et al. Cutting edge: the mechanism of invariant NKT cell responses to viral danger signals. J Immunol. 2008;181(7):4452-4456.

24. Iyoda T, et al. Invariant NKT cell anergy is induced by a strong TCR-mediated signal plus costimulation. Int Immunol. 2010;22(11):905-913.

25. Tonti E, et al. Follicular helper NKT cells induce limited B cell responses and germinal center formation in the absence of CD4(+) T cell help. JImmunol. 2012;188(7):3217-3222.

26. Chang P-P, et al. Identification of Bcl-6-dependent follicular helper NKT cells that provide cognate help for B cell responses. Nat Immunol. 2011;13(1):35-43.

27. Baine I, Abe BT, Macián F. Regulation of T-cell tolerance by calcium/NFAT signaling. Immunol Rev. 2009;231(1):225-240.

28. Zheng Y, Zha Y, Gajewski TF. Molecular regulation of T-cell anergy. EMBO Rep. 2008;9(1):50-55.

29. Sakaguchi S. Regulatory T cells: history and per- spective. Methods Mol Biol. 2011;707:3-17.

30. Madan R, et al. Nonredundant roles for B cellderived IL-10 in immune counter-regulation. JImmunol. 2009;183(4):2312-2320.

31. Corish P, Tyler-Smith C. Attenuation of green fluorescent protein half-life in mammalian cells. Protein Eng. 1999;12(12):1035-1040.

32. Biburger M, Tiegs G. Activation-induced NKT cell hyporesponsiveness protects from $\alpha$-galactosylceramide hepatitis and is independent of active transregulatory factors. J Leukoc Biol. 2008;84(1):264-279.

33. Constantinides MG, Bendelac A. Transcriptional regulation of the NKT cell lineage. Curr Opin Immunol.2013;25(2):161-167.

34. Lee YJ, Holzapfel KL, Zhu J, Jameson SC, Hogquist KA. Steady-state production of IL-4 modulates immunity in mouse strains and is determined by lineage diversity of iNKT cells. Nat Immunol. 2013;14(11):1146-1154.

35. Watarai $\mathrm{H}$, et al. Development and function of invariant natural killer $\mathrm{T}$ cells producing T(h)2- and T(h)17-cytokines. PLoS Biol. 2012;10(2):e1001255.

36. Moreira-Teixeira L, et al. Rapamycin combined with TGF- $\beta$ converts human invariant NKT cells into suppressive Foxp3+ regulatory cells. JImmunol. 2012;188(2):624-631.

37. Monteiro $\mathrm{M}$, et al. Identification of regulatory Foxp3+ invariant NKT cells induced by TGF- $\beta$. J Immunol. 2010;185(4):2157-2163.

38. King IL, et al. Invariant natural killer T cells direct $B$ cell responses to cognate lipid antigen in an IL-21-dependent manner. Nat Immunol. 2011;13(1):44-50.

39. Milpied P, et al. IL-17-producing invariant NKT cells in lymphoid organs are recent thymic emigrants identified by neuropilin-1 expression. Blood. 2011;118(11):2993-3002.

40. Coquet JM, et al. Diverse cytokine production by NKT cell subsets and identification of an IL-17-producing CD4-NK1.1- NKT cell population. Proc Natl Acad Sci U S A. 2008;105(32):11287-11292.

41. Michel ML, et al. Identification of an IL-17-producing NK1.1neg iNKT cell population involved in airway neutrophilia. J Exp Med. 2007;204(5):995-1001.

42. Doisne JM, et al. Skin and peripheral lymph node invariant NKT cells are mainly retinoic acid receptor-related orphan receptor (gamma)t+ and respond preferentially under inflammatory conditions. J Immunol. 2009;183(3):2142-2149.

43. Baxter AG. The origin and application of experimental autoimmune encephalomyelitis. Nat Rev Immunol. 2007;7(11):904-912.

44. Singh AK, et al. Natural killer T cell activation protects mice against experimental autoimmune encephalomyelitis. JExp Med. 2001;194(12):1801-1811.

45. Jahng AW, et al. Activation of natural killer $\mathrm{T}$ cells potentiates or prevents experimental autoimmune encephalomyelitis. J Exp Med. 2001;194(12):1789-1799.

46. Furlan R, et al. Activation of invariant NKT cells by alphaGalCer administration protects mice from MOG35-55-induced EAE: critical roles for administration route and IFN- $\gamma$. Eur JImmunol.
2003;33(7):1830-1838.

47. Parekh VV, et al. Quantitative and qualitative differences in the in vivo response of NKT cells to distinct $\alpha$ - and $\beta$-anomeric glycolipids.

JImmunol. 2004;173(6):3693-3706.

48. Miyamoto K, Miyake S, Yamamura T. A synthetic glycolipid prevents autoimmune encephalomyelitis by inducing $\mathrm{TH} 2$ bias of natural killer $\mathrm{T}$ cells. Nature. 2001;413(6855):531-534.

49. Pal E, et al. Costimulation-dependent modulation of experimental autoimmune encephalomyelitis by ligand stimulation of $\mathrm{V} \alpha 14 \mathrm{NK} T$ cells. JImmunol. 2001;166(1):662-668.

50. Qian G, et al. High doses of $\alpha$-galactosylceramide potentiate experimental autoimmune encephalomyelitis by directly enhancing Th17 response. Cell Res. 2010;20(4):480-491.

51. Wilson MT, et al. The response of natural killer $\mathrm{T}$ cells to glycolipid antigens is characterized by surface receptor down-modulation and expansion. Proc Natl Acad Sci U S A. 2003;100(19):10913-10918.

52. Crowe NY, et al. Glycolipid antigen drives rapid expansion and sustained cytokine production by NK T cells. JImmunol. 2003;171(8):4020-4027.

53. Huh JY, et al. A novel function of adipocytes in lipid antigen presentation to iNKT cells. Mol Cell Biol. 2013;33(2):328-339.

54. Ji Y, et al. Activation of natural killer T cells promotes M2 Macrophage polarization in adipose tissue and improves systemic glucose tolerance via interleukin-4 (IL-4)/STAT6 protein signaling axis in obesity. J Biol Chem. 2012;287(17):13561-13571.

55. Lynch L, et al. Adipose tissue invariant NKT cells protect against diet-induced obesity and metabolic disorder through regulatory cytokine production. Immunity. 2012;37(3):574-587.

56. Parekh VV, et al. PD-1/PD-L blockade prevents anergy induction and enhances the anti-tumor activities of glycolipid-activated invariant NKT cells. JImmunol. 2009;182(5):2816-2826.

57. Terashima A, et al. A novel subset of mouse NKT cells bearing the IL-17 receptor B responds to IL-25 and contributes to airway hyperreactivity. JExp Med. 2008;205(12):2727-2733.

58. Sonoda KH, et al. NK T cell-derived IL-10 is essential for the differentiation of antigen-specific $\mathrm{T}$ regulatory cells in systemic tolerance. JImmunol. 2001;166(1):42-50.

59. Lynch L, et al. Invariant NKT cells and CD1d(+) cells amass in human omentum and are depleted in patients with cancer and obesity. Eur Immunol. 2009;39(7):1893-1901.

60. Schipper HS, et al. Natural killer T cells in adipose tissue prevent insulin resistance. JClin Invest. 2012;122(9):3343-3354

61. Mars LT, et al. Cutting edge: V $\alpha 14-J \alpha 281$ NKT cells naturally regulate experimental autoimmune encephalomyelitis in nonobese diabetic mice. J Immunol. 2002;168(12):6007-6011.

62. Singh N, et al. Cutting edge: activation of NK T cells by CD1d and $\alpha$-galactosylceramide directs conventional $\mathrm{T}$ cells to the acquisition of a Th2 phenotype. J Immunol. 1999;163(5):2373-2377.

63. Matsuda JL, et al. Mouse V alpha 14i natural killer $\mathrm{T}$ cells are resistant to cytokine polarization in vivo. Proc Natl Acad Sci U S A. 2003;100(14):8395-8400. 
64. Oh SJ, Chung DH. Invariant NKT cells producing IL-4 or IL-10, but not IFN- $\gamma$, inhibit the Th1 response in experimental autoimmune encephalomyelitis, whereas none of these cells inhibits the Th17 response. JImmunol. 2011;186(12):6815-6821.

65. Denney L, et al. Activation of invariant NKT cells in early phase of experimental autoimmune encephalomyelitis results in differentiation of Ly6Chi inflammatory monocyte to M2 macrophages and improved outcome. JImmunol. 2012;189(2):551-557.

66. Parekh VV, Wu L, Olivares-Villagómez D,
Wilson KT, Van Kaer L. Activated invariant NKT cells control central nervous system autoimmunity in a mechanism that involves myeloid-derived suppressor cells. J Immunol. 2013;190(5):1948-1960.

67. Mars LT, et al. Invariant NKT cells inhibit development of the Th17 lineage. Proc Natl Acad Sci US A. 2009;106(15):6238-6243.

68. Kojo S, et al. Induction of regulatory properties in dendritic cells by Va14 NKT cells. J Immunol. 2005;175(6):3648-3655.

69. Sharif S, et al. Activation of natural killer T cells by $\alpha$-galactosylceramide treatment prevents the onset and recurrence of autoimmune Type 1 diabetes. Nat Med.2001;7(9):1057-1062.

70. Hong S, et al. The natural killer T-cell ligand $\alpha$-galactosylceramide prevents autoimmune diabetes in non-obese diabetic mice. Nat Med. 2001;7(9):1052-1056.

71. Wingender G, et al. Invariant NKT cells are required for airway inflammation induced by environmental antigens. J Exp Med. 2011;208(6):1151-1162.

72. Barrett T, et al. NCBI GEO: archive for functional genomics data sets -10 years on. Nucleic Acids Res. 2010;39(Database issue):D1005-D1010. 